\title{
Methyltransferase-Glo: a universal, bioluminescent and homogenous assay for monitoring all classes of methyltransferases
}

\begin{abstract}
Aim: To develop a homogenous, nonradioactive, antibody-free and universal assay for diverse families of methyltransferases and monitor the activity of these enzymes in a high-throughput format. Materials \& methods: The assay conditions are optimized for monitoring the enzymatic activity of a broad range of methyltransferases regardless of the chemical structure or nature of the enzyme substrate in a low- and high-throughputformatted protocols. The assay detects S-adenosyl-L-homocysteine, the universal reaction products of all methyltransferases. Results: We demonstrate the utility of using this protocol to determine the activity of DNA, protein methyltransferases and also to determine kinetic parameters of several inhibitors using purified enzymes. The assay is sensitive (20-30 nM of S-adenosyl-L-homocysteine) and robust. Conclusion: The methyltransferase Glo is nonradioactive, antibody-free and homogenous, universal assay to determine enzyme activity of diverse families of methyltransferases. The assay is formatted to meet the requirements of high-throughput screening in drug discovery programs searching for modulators of methyltransferases.
\end{abstract}

First draft submitted: 24 August 2015; Accepted for publication: 1 December 2015; Published online: 7 March 2016

Keywords: compound screening $\bullet$ enzyme activity $\bullet$ epigenetics $\bullet$ high-throughput assay - homogenous $\bullet$ inhibitors $\bullet$ luminescence $\bullet$ methylation $\bullet$ methyltransferase $\bullet$ universal

Epigenetics is the branch of cell biology that addresses the effect of environmental changes on gene expression which results in a selective phenotype $[1,2]$. It includes the study of molecular, cellular and environmental aspects of genetics, that is, any changes in the phenotypes that are independent of DNA sequences. Epigenetics therefore describes processes that alter chromatin structure without change in gene sequences $[1,2]$. Chromatin modulation occurs via posttranscriptional modifications of chromatin proteins such as histones by phosphorylation, acetylation and methylation, etc. resulting in alteration of chromatin transcriptional activity $[1,3]$. Thus, epigenetic disruptions play a pivotal role in tumor invasion, and progression for many different types of cancer $[4,5]$. In addition to the alteration of transcriptional activity by phosphorylation of transcription factors, methylation also appears to play a prominent role in transcription by modulating chromatin and consequently, any changes in methyltransferase activities as well as alterations in methylation sites within chromatin appears to be implicated in several abnormalities in cell growth [3].

It appears that methylation of cellular proteins and nucleic acids is extensive, and the enzymes catalyzing these reactions utilize wide range of substrates such as histones, nonhistone proteins, nucleic acids and small molecules [6-15].

In a methyltransferase reaction $S$-adenosylmethionine (SAM) is used as a universal methyl donor to produce S-adenosylhomocysteine (SAH) as a universal product of the reaction, in addition to the methylated
Kevin Hsiao', Hicham Zegzouti' \& Said A Goueli*,1,2 'Promega Corporation, R\&D Department, 2800 Woods Hollow Road, Madison, WI 53711, USA

2Department of Pathology \& Laboratory Medicine, University of Wisconsin School of Medicine \& Public Health, Madison, WI 53726, USA

*Author for correspondence:

Tel.: + 16082772650

sgoueli@promega.com
Future $\%$
Medicine ${ }_{\text {part of }}$ fss 
acceptor substrate. It is noteworthy that SAM is not only an intermediate metabolite in methionine catabolism but it is also a regulator of essential liver functions such as liver regeneration, differentiation and sensitivity to injury [16]. Furthermore, SAM concentration is important in the regulation of homocysteine which is a risk factor for cardiovascular diseases and patient treatment with SAM improved many diverse disorders of the central nervous system such as depression and great improvements in treatment of liver diseases [17]. Methylation of other substrates such as hormones, neurotransmitters and signal transduction systems control their regulatory roles, and methylation of phospholipids keeps the membrane fluid and maintain receptors mobility. The strong preference for SAM as a methyl donor over others such as folate is due to its favorable thermodynamics in methyltransferase reactions [18].

Because of their involvement in diverse cellular processes such as chromatin modulation, cellular proliferation, differentiation and apoptosis, among others, methyltransferases are recognized as validated drug targets for several cellular pathologies such as cancer and inflammation [19-21]. Consequently, there is heightened interest in developing assays that monitor the activity of these enzymes to enable screening of large library of compounds in order to develop potential future drug candidates [22-24]. To address these needs, several strategies were developed to assay for the activity of these enzymes. These include radioactivity-based assay [25,26], fluorogenic substrates [27], antibody-based fluorescent assay [28], antibody-based chemiluminescent assay [29,30], luminescent assays [31-33] and mass spectroscopy (MS)-based assays [34]. These different approaches were discussed in a recent review [9]. All the assays above except MS-based assays are biochemical. In contrast to the above described assays which are biochemical, that is, monitoring the activity of purified enzymes, MS-based methods quantify changes in the methylation status of the substrate since many methyltransferases transfer more than one methyl group to selective lysine or arginine and the ability to measure the levels of each methylated species can provide valuable information. Furthermore, MS can determine the amount of unmethylated, monomethylated, dimethylated and trimethylated peptides present. These are the main limitation of the other biochemical methods. MS-based technologies however require specialized equipment and expertise, and they are limited to lowor medium-throughput screening but can be used for secondary screening [34].

An ideal assay should meet the major requirements of drug research with minimal undesirable features if possible. The assay should be sensitive, amenable to high-throughput formats to provide the throughput and robustness [35] to ensure the reliability of the data generated from the assay, and it should not be subject to interference from fluorescent compounds as is the case with many fluorescent-based assays [27,28]. Preferably, the assay should be antibody free to minimize changes in assay performance due to fluctuations in antibody quality, cross-reactivity or affinity as well as optimization of the amount of antibody required to capture the generated product. The assay should be nonradioactive to eliminate user safety concerns due to exposure to radioactivity as well as the related cost of disposing radioactive waste. Finally, the assay is best if it is

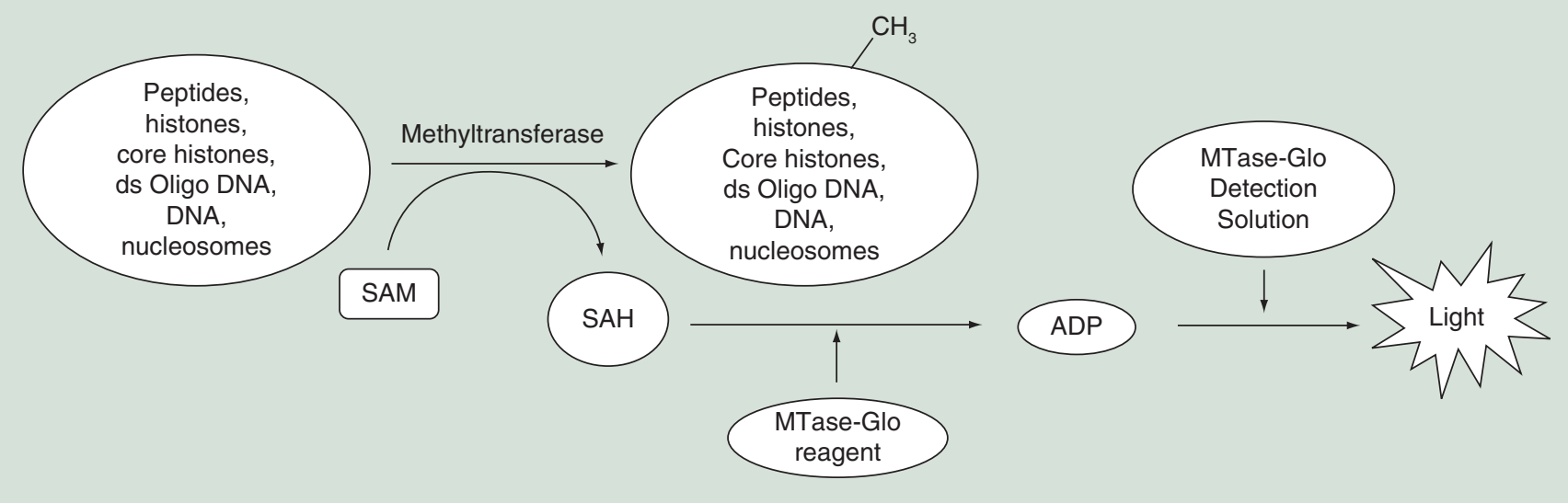

Figure 1. Principle of the universal MTase-Glo assay. Upon completion of the methyltransferase reaction using any substrate/enzyme combination and the substrate SAM and generating the universal reaction product SAH, MTase-Glo Reagent is added to convert SAH to ADP. This is followed by the addition of MTase-Glo ${ }^{\mathrm{TM}}$ Detection Solution to convert ADP to ATP which is measured using a luciferase/luciferin reaction. The light generated is proportional to SAH present produced in the methyltransferase reaction. The luminescence signal is stable with a half-life greater than $4 \mathrm{~h}$, and thus eliminating the need for injector equipped luminometers and allows for batch mode processing of multiple plates. ds: Double stranded; SAH: S-adenosyl-homocysteine; SAM: S-adenosyl-methionine. 
(A)

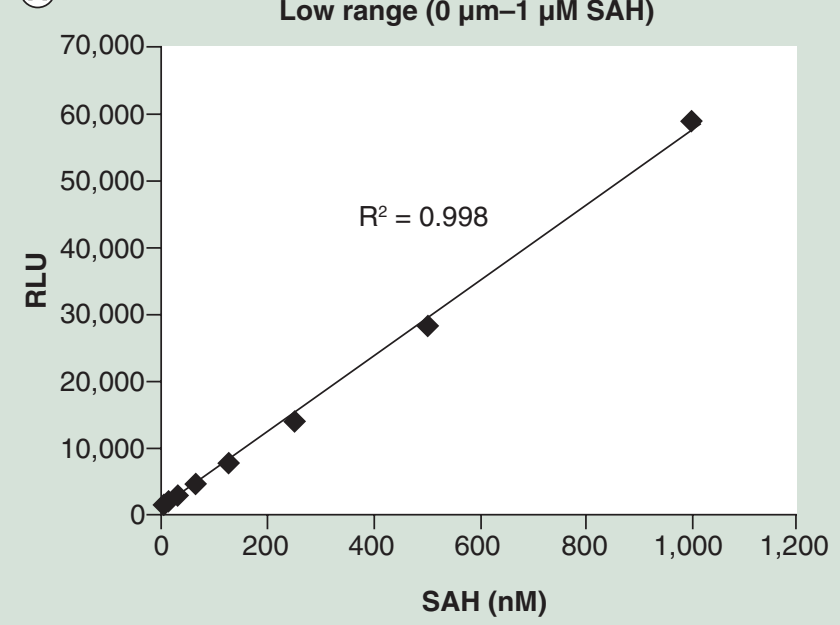

(B)

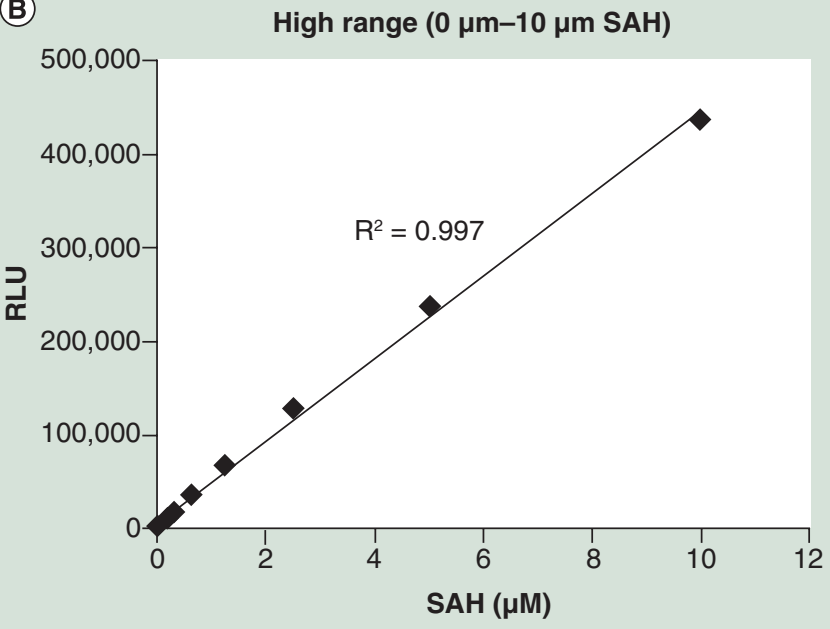

(C)

\begin{tabular}{|c|cccccccccccc|}
\hline SAH, nM & $\mathbf{1 0 0 0}$ & $\mathbf{5 0 0}$ & $\mathbf{2 5 0}$ & $\mathbf{1 2 5}$ & $\mathbf{6 2 . 5}$ & $\mathbf{3 1 . 2 5}$ & $\mathbf{1 5 . 6 3}$ & $\mathbf{7 . 8 1}$ & $\mathbf{3 . 9 1}$ & $\mathbf{1 . 9 5}$ & $\mathbf{0 . 9 8}$ & $\mathbf{0}$ \\
\hline RLU & 59,105 & 28,506 & 13,886 & 7684 & 4623 & 3190 & 2406 & 2005 & 1926 & 1760 & 1789 & 1563 \\
\hline S/B & 37.8 & 18.2 & 8.9 & 4.9 & 3.0 & 2.0 & 1.5 & 1.3 & 1.2 & 1.1 & 1.1 & 1.0 \\
\hline S/N & 596 & 279 & 128 & 63 & 32 & 17 & 9 & 5 & 4 & 2 & 2 & 0 \\
\hline
\end{tabular}

RLU: An average of light output from quadruplicates

STDEV: Standard deviation, STDEV of background is $97 \mathrm{RLU}$

$\mathrm{S} / \mathrm{B}$ : Mean of signal/mean of background

$\mathrm{S} / \mathrm{N}$ : (Mean of signal-mean of background)/(STDEV of background)

Figure 2. S-adenosyl-homocysteine titration using MTase-Glo assay. Standard concentrations of SAH were detected using MTaseGlo assay in low-volume 384-well solid white plates as described under 'Materials \& methods'. (A \& B) luminescence was recorded within 30 min after addition of the Detection Solution using the Infinite ${ }^{\circledR}$ M1000 PRO plate-reader luminometer (Tecan). (C) is a table showing the RLU generated at various SAH concentrations and S/B and S/N. The value S/N is calculated as the difference between the mean of the signal and the mean of the background divided by the standard deviation of the background. Limit of detection is $3 \times(S / N)$. Data were analyzed using Excel software and represented as mean \pm standard error $(n=4)$.

RLU: Relative luminescence unit; SAH: S-adenosyl-homocysteine; SAM: S-adenosyl-methionine; S/B: signal:background ratio; $\mathrm{S} / \mathrm{N}$ : Signal-to-noise ratio.

homogenous and universal, that is, can be used with any enzyme-substrate combinations with no change in the assay format is needed whenever a new substrate needs to be tested. Here, we report on the development of a bioluminescent and homogenous methyltransferase assay that is robust and universal, and meets most if not all of the positive features described above. This assay is shown to be capable of monitoring the activity of diverse set of methyltransferases. Simplicity and convenience are two additional features of this assay and these are highly desirable for any research project.

\section{Materials \& methods Instrumentations}

Luminescence Microplate Reader (Luminometer): any commercial multimode microplate luminescent readers can be used such as Infinite ${ }^{\circledR}$ M1000 PRO or Infinite ${ }^{\circledR}$ F500, Tecan Group Ltd, Switzerland or GloMax ${ }^{\circledR}$ Discover System, Promega Corporation, Madi- son, WI, USA or equivalent. Assay plates: 96-well and low-volume 384-well nontreated white polystyrene or EIA/RIA plate 96-well half area nontreated white polystyrene (Corning Costar: 3912, 3693, 3572 and 4512, Corning Inc., Corning, NY, USA) or equivalent.

\section{Enzymes \& substrates reagents}

Protein methyltransferases: EHMT2-G9a; SET7/9; PRMT1, PRMT4 and PRMT5 (MEP50) and DOT1L were obtained from BPS Bioscience Inc. (San Diego, CA, USA). EZH1 complex; EZH2 complex; and DNA methyltransferase 1 and $3 a$ were purchased from Reaction Biology Corp (Malvern, PA, USA).

Substrate peptides: histone $\mathrm{H} 3$-derived peptide (H3 [1-25]), (H3 [21-44]), (H3 [69-89]) and histone H4-derived peptide (H4[1-20]) were from AnaSpec Inc. (Fremont, CA, USA). Full-length histone 3 His$\operatorname{tag}(\mathrm{H} 3)$ and full-length histone 4 His-tag $(\mathrm{H} 4)$ were obtained from BPS Bioscience Inc. (San Diego, CA, 
USA). Mononucleosomes and oligonucleosomes were from Reaction Biology Corp. (Malvern, PA, USA). ds-oligo DNA was synthesized by Integrated DNA Technologies, Inc. (Coralville, Iowa).

\section{Chemicals \& assay components}

GSK126 was purchased from Xcess Biosciences, Inc. (San Diego, CA, USA), trifluoroacetic acid and dimethyl sulfoxide (DMSO) was purchased from Sigma-Aldrich Co. LLC (St. Louis, MO, USA). For arginine and lysine protein specific methyltransferase reactions, buffer contains $20 \mathrm{mM}$ Tris/ $\mathrm{HCl}, \mathrm{pH} 8.0$, $50 \mathrm{mM} \mathrm{NaCl}, 1 \mathrm{mM}$ EDTA, $3 \mathrm{mM} \mathrm{MgCl} 2,0.1 \mathrm{mg} / \mathrm{ml}$ BSA and $1 \mathrm{mM}$ DTT. For DNA methyltransferases reactions, buffer contains $20 \mathrm{mM}$ Tris/ $\mathrm{HCl}, \mathrm{pH} 7.4$, $0.5 \mathrm{mM}$ EDTA, $3 \mathrm{mM} \mathrm{MgCl} 2,0.1 \mathrm{mg} / \mathrm{ml} \mathrm{BSA}$ and $0.2 \mathrm{mM}$ DTT. Methyltransferase-Glo assay kit from Promega Corporation (Madison, WI, USA) contains Methyltransferase-Glo Reagent ( $400 \mathrm{mM}$ tris buffer, $\mathrm{pH}$ 8.0, $40 \mathrm{mM} \mathrm{MgCl}$, 75 mM NaCl,125 $\mu \mathrm{M}$ dGTP, $200 \mu \mathrm{M}$ sodium metaphosphate, $80 \mu \mathrm{g} / \mathrm{ml}$ polyphosphate - AMP phosphotransferase [PAP], $200 \mu \mathrm{g} / \mathrm{ml}$ SAH-Hydrolase, $50 \mu \mathrm{g} / \mathrm{ml}$ adenosine kinase [Adk], $5 \mathrm{mM}$ DTT), methyltransferase-Glo detection solution $(1 \mathrm{mM}$ potassium phosphoenolpyruvate, $8 \mathrm{U} / \mathrm{ml}$ pyruvate kinase in Kinase-Glo reagent (Promega Cat\# V6711), SAM substrate and SAH as a standard. SAM and $\mathrm{SAH}$ were ordered from Sigma Chemical Co;
SAM: Cat\# A7007 and SAH-Cat\# A9384, and were purified using HPLC, both are available from Promega Cat\# A120A (SAM) and Cat\# A233A (SAH).

\section{Methyltransferase-Glo assay general protocol}

The MTase-Glo assay can be performed in two different ways. Two-step assay: in a 384-well plates, $4 \mu \mathrm{l}$ of an SAH containing solution was added per well followed by the addition of $1 \mu \mathrm{l}$ of $0.5 \%$ trifluoroacetic acid (TFA) to stop the reaction. After a brief mixing, $1 \mu \mathrm{l}$ of 6X Methyltransferase-Glo Reagent was added, mixed well and incubated at $23^{\circ} \mathrm{C}$ for $30 \mathrm{~min}$. Then, a $6 \mu \mathrm{l}$ Methyltransferase-Glo Detection Solution was added and mixed well before incubating for another $30 \mathrm{~min}$ and recording luminescence using a luminometer. Onestep assay: in a 384-well plates, methyltransferase reaction is performed in the presence of MethyltransferaseGlo Reagent in $5 \mu \mathrm{l}$ total volume for the required time to produce SAH and concomitantly convert it to ADP. Then, $5 \mu$ l Methyltransferase-Glo Detection Solution was added and mixed well before incubating for another $30 \mathrm{~min}$ and recording luminescence.

It is noteworthy to mention that the assay format is flexible, that is, volumes of the standards or SAH producing reactions as well as the reagent volumes can be maintained at the ratio of 4:1:5 (methylation reaction: Methyltransferase-Glo Reagent: Methyltransferase-Glo Detection Solution). Thus, for example, for

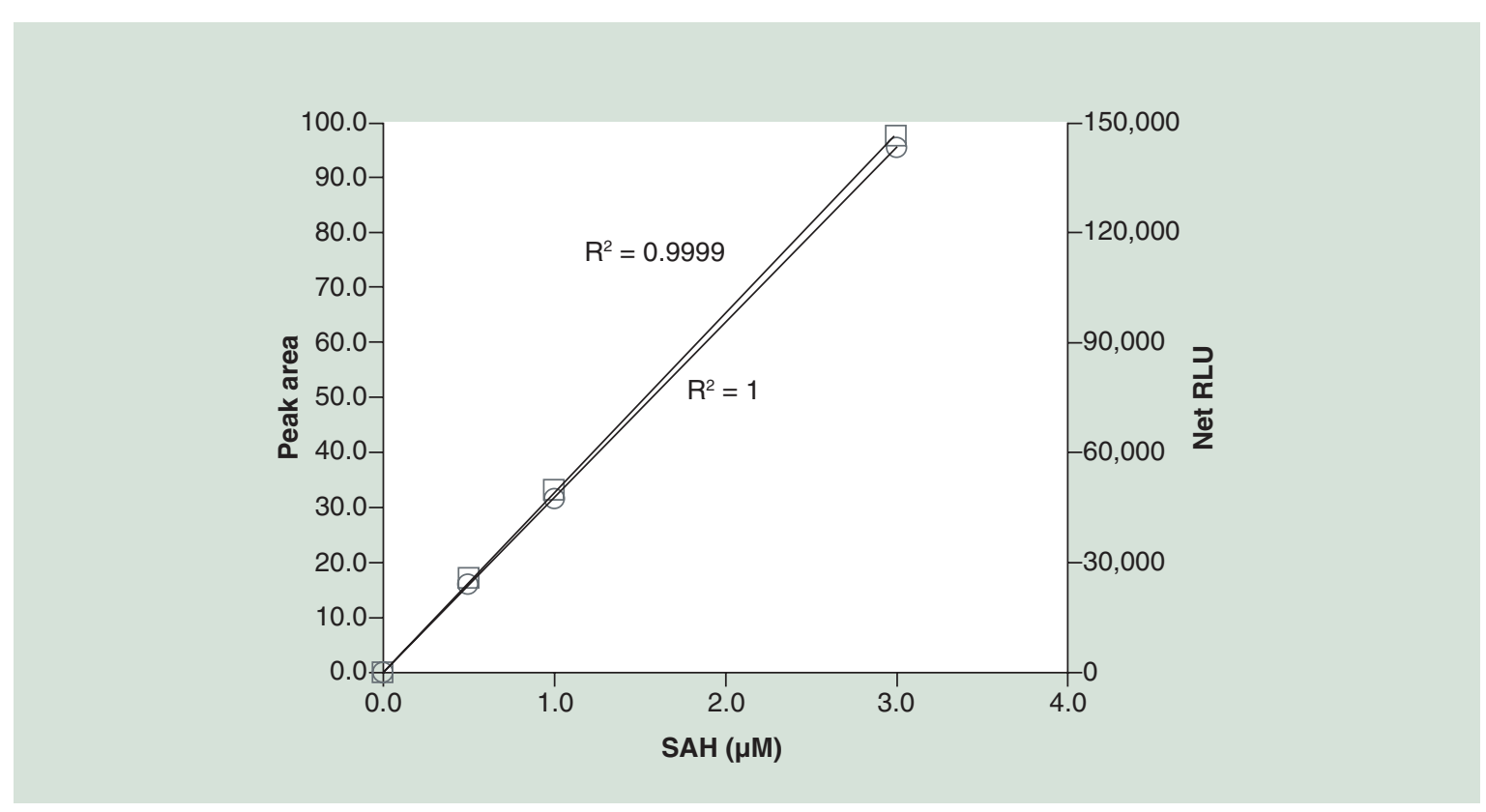

Figure 3. S-adenosyl-homocysteine titration using MTase-Glo and HPLC methods. Standard concentrations of SAH were detected using MTase-Glo assay in low-volume 384-well solid white plates as described in 'Materials \& methods'. Identical concentrations of SAH were also run on HPLC and areas under the SAH peak generated by HPLC (open circles) were integrated and plotted against RLUs values generated for the same concentration of SAH (open squares). Data were analyzed using Excel software and represented as means \pm standard errors $(n=4)$. RLU: Relative luminescence unit; SAH: S-adenosyl-homocysteine. 
(A)

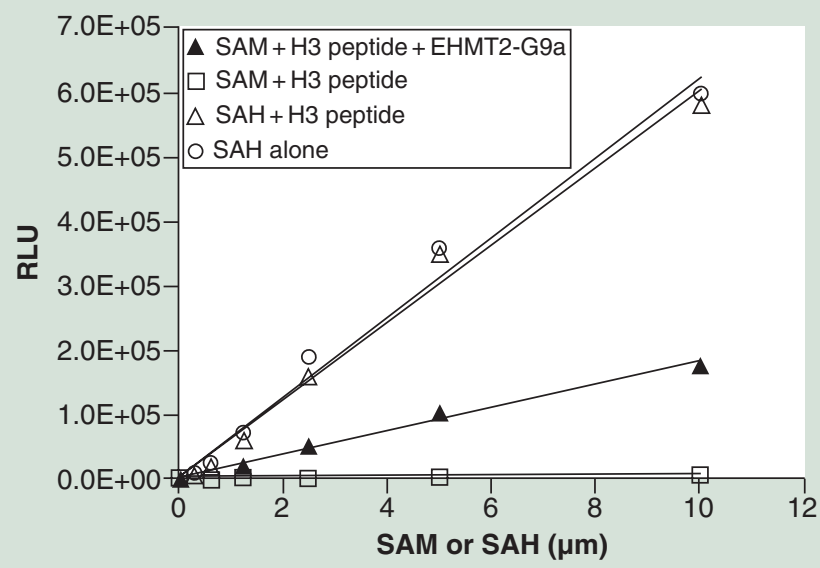

(C)

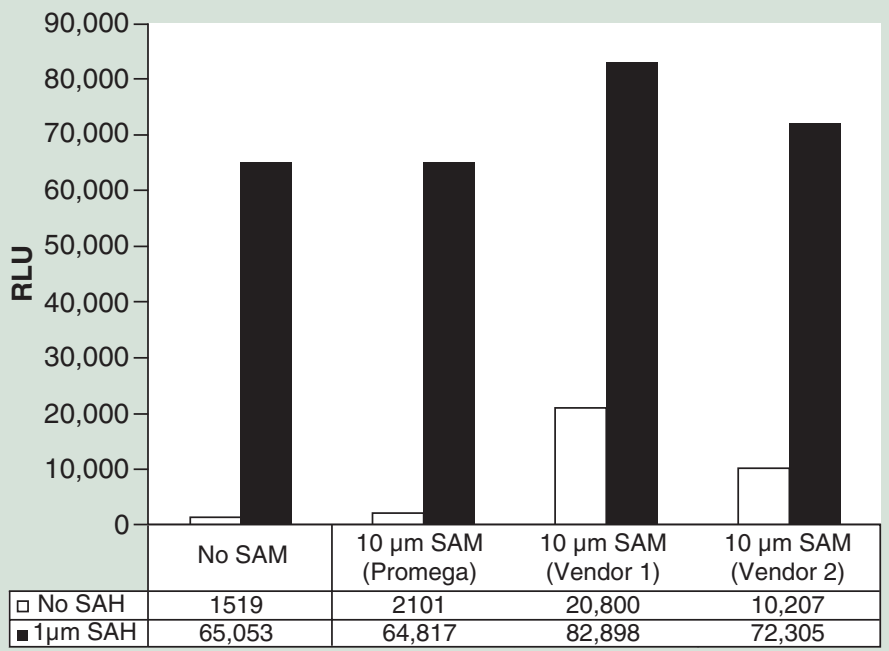

(B)

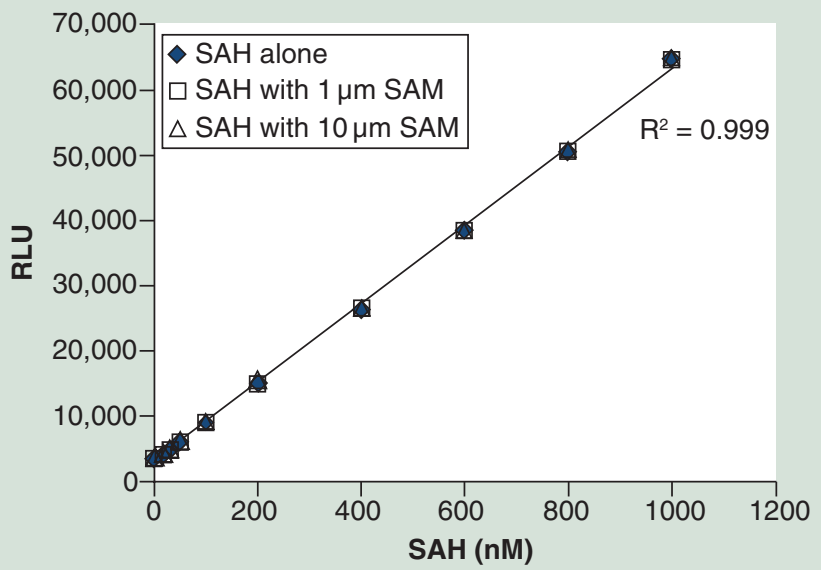

(D)

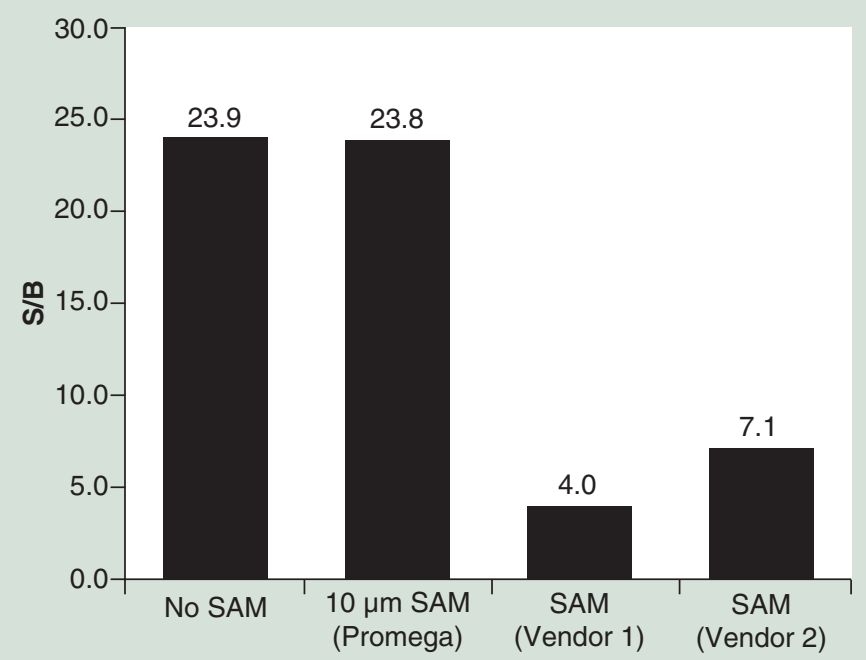

Figure 4. Effect of the purity of S-adenosyl-methionine on the detection of S-adenosyl-homocysteine using MTase-Glo assay. (A) SAH and SAM were titrated in the presence of $10 \mu \mathrm{M} \mathrm{H} 3$ peptide and $1 \mathrm{ng}$ EHMT2 G9a methyltransferase for 60 min at room temp. SAH and methyltransferase-generated SAH were detected by MTase-Glo and the SAM effect on the detection system was assessed. (B) Different concentrations of SAH were monitored in the presence of $1 \mu \mathrm{M}$ or $10 \mu \mathrm{M}$ of SAM using MTase-Glo assay to assess any background levels coming from SAM. To compare the level of SAH background generated from different sources of SAM, $1 \mu \mathrm{M}$ SAH was detected in the absence or presence of $10 \mu \mathrm{M}$ highly purified SAM or $10 \mu \mathrm{M}$ SAM purchased from commercial sources. The data are reported as a luminescent signal generated in absolute RLUs (C) and signal to background ratio (D). The MTase-Glo assay was performed as described in 'Materials \& methods' in low-volume 384-well solid white plates. Luminescence was measured using the Infinite ${ }^{\circledR}$ M1000 PRO plate-reading luminometer (Tecan). Data were analyzed using Excel ${ }^{\circledR}$ software and represented as mean $(n=4)$. RLU: Relative luminescence unit; SAH: S-adenosyl-homocysteine; SAM: S-adenosyl-methionine; S/B: Signal:background ratio.

96-well format, we recommend using $8 \mu \mathrm{l}: 2 \mu \mathrm{l}: 10 \mu \mathrm{l}$ or multiples of these volumes. For a two-step assay: the ratio of 5:1:6 (Methylation reaction/TFA: Methyltransferase-Glo Reagent: Methyltransferase-Glo Detection Solution) is used.

\section{SAH standard curve}

$\mathrm{SAH}$ standard curve was prepared using protein methyltransferase buffer to assess the linearity of the assay and for enzyme titrations in order to calculate the amount of SAH produced from each enzyme concentration used. We ran two standard curves, one from 0 to $1 \mu \mathrm{M}$ and the other from 0 to $10 \mu \mathrm{M}$ to get information on the sensitivity of the assay as well as linear range of its usage. First, we prepare $1 \mu \mathrm{M}$ and $10 \mu \mathrm{M} \mathrm{SAH}$ stock solutions and performed serial dilutions from each concentration of the standard in methyltransferase reaction buffer. Then, $4 \mu \mathrm{l}$ of an 


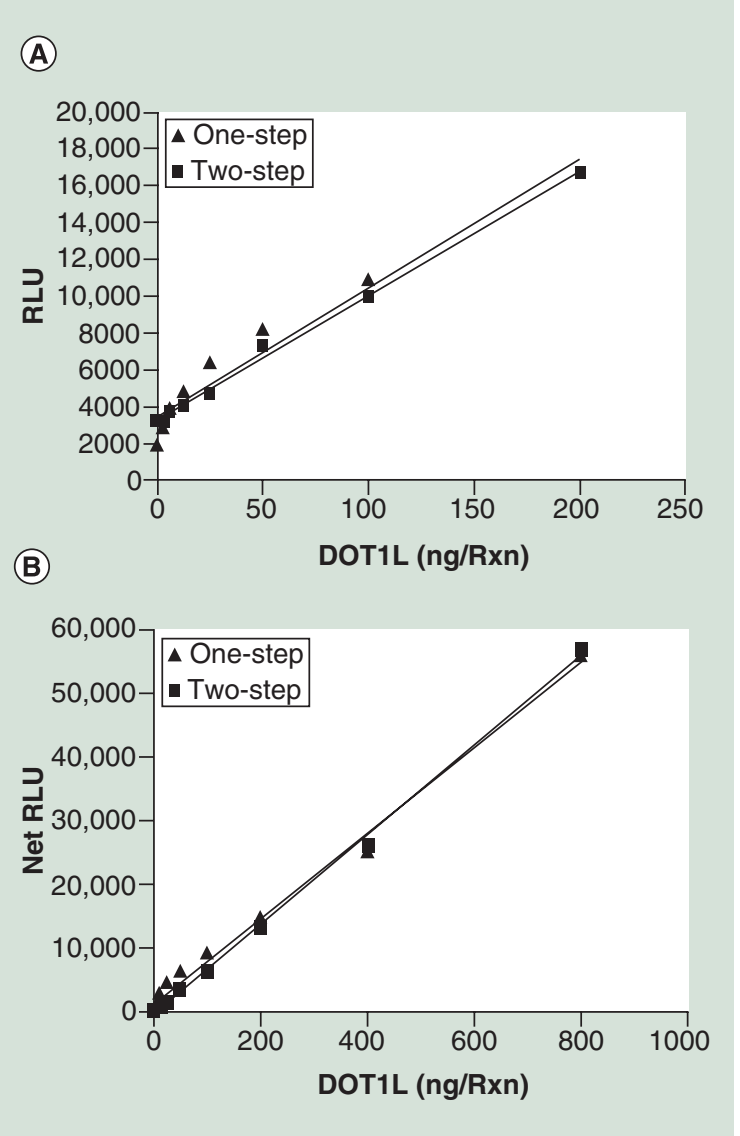

Figure 5. Comparison of one-step and two-step MTase-Glo assay protocols using DOT1L methyltransferase reaction. DOT1L was diluted to the indicated concentrations with reaction buffer in a solid white low-volume 384-well plate in presence of $1 \mu \mathrm{M} \mathrm{S}$-adenosyl-methionine and $50 \mu \mathrm{g} / \mathrm{ml}$ of mono/di-nucleosome and the one-, or two-step assays were performed as described in 'Materials \& methods'. In one-step assay, enzyme reactions were carried out with MTase-Glo reagent included with DOT1L samples for $60 \mathrm{~min}$ reaction at $23^{\circ} \mathrm{C}$, then followed with the addition of MTase-Glo detection solution. For two-step assay, enzyme reactions were performed at $23^{\circ} \mathrm{C}$ for $60 \mathrm{~min}$, then trifluoroacetic acid was added to final concentration of $0.1 \%$ to stop enzyme reaction, then followed with MTase-Glo reagent followed by the addition of MTase-Glo detection solution. Both protocols were processed as described in the MTase-Glo assay under 'Materials \& methods'. Luminescence was measured using the Infinite ${ }^{\circledR}$ M1000 PRO plate-reading luminometer (Tecan). Data were analyzed using Excel ${ }^{\circledR}$ software and represented as mean \pm standard error $(n=4)$. Data were plotted using absolute RLU values (A) as well as Net RLUs after subtraction of background RLUs (B). It is apparent that there was no noticeable difference in the activity of the enzyme either using one-step or two-step protocol.

RLU: Relative luminescence unit.

SAH serial dilutions was transferred to a 384-well plates followed by addition of the detection reagents using the methyltransferase-Glo protocol described above.

\section{Methyltransferase assay conditions}

Generally, all methyltransferase reactions were performed in protein methyltransferase reaction buffer. All different classes of methyltransferase reactions were performed in $4 \mu \mathrm{l}$. PRMT5/MEP50, DOT1L and EHMT2-G9a reactions were performed at room temperature $\left(23^{\circ} \mathrm{C}\right)$, DNMT3a, EZH1 and EZH2 complex reactions were performed at $37^{\circ} \mathrm{C}$. PRMT5/MEP50 complex reaction contained $20 \mu \mathrm{M}$ SAM and $20 \mu \mathrm{M}$ H4-derived (1-20) peptide and incubated for $30 \mathrm{~min}$. EHMT2-G9a reactions contained $20 \mu \mathrm{M}$ SAM and $20 \mu \mathrm{M} \mathrm{H} 3-(1-25)$ peptide. DNMT3a reactions contained $10 \mu \mathrm{M}$ SAM and $10 \mathrm{nM}$ ds oligodeoxynucleotide:

5' A12-GAT CCG ACG ACG ACG CGC GCG CGA CGA CGA GAT C

3' CTA GGC TGC TGC TGC GCG CGC GCT GCT GCT CTA G-A12

DOT1L reaction contained $20 \mu \mathrm{M}$ SAM and $0.5 \mu \mathrm{g}$ HeLa Oligo nucleosome and incubated for $60 \mathrm{~min}$. All reactions were incubated for $60 \mathrm{~min}$ at the temperature listed above. Upon completion of the methyltransferase reaction, $1 \mu \mathrm{l}$ of a $0.5 \%$ TFA was added to terminate the reaction and the detection reagents were added and the Mmethyltransferase-Glo protocol described above was followed before recording luminescence.

\section{Inhibitor study using methyltransferase-glo assay}

To determine the $\mathrm{IC}_{50}$ value of GSK126 inhibition of EZH2 complex, $10 \mu \mathrm{l}$ reactions were assembled with $0.5 \mu \mathrm{g}$ of EZH2 enzyme, and $0,0.5,1$ or $5 \mu \mathrm{M}$ SAM with $10 \mu \mathrm{M} \mathrm{H} 3$ protein as the substrate and a serial dilution of the inhibitor GSK126 in a solid white lowvolume 384-well plate and were incubated for $60 \mathrm{~min}$ at $30^{\circ} \mathrm{C}$. For determining the inhibition mode of action of sinefungin on EHMT2-G9a, we used 2 ng of EHMT2G9a per reaction with $50 \mu \mathrm{M}$ histone 3 derived (1-25) peptide, with $2 \mu \mathrm{M}$ or $10 \mu \mathrm{M}$ SAM and the indicated concentrations of sinefungin in a solid white low-volume 384 -well plate and incubated for 60 minutes at $23^{\circ} \mathrm{C}$. After incubation, MTase-Glo assay was performed as described in previous section 'Materials \& methods'. The luminescence was recorded and $\mathrm{IC}_{50}$ values were determined using Excel ${ }^{\circledR}$ software and GraphPad Prism 6. Each data point represents the average of two replicates; the error bars represent the standard deviation.

\section{$Z^{\prime}$-factor determination}

The Z' factor values were determined using two substrates (SAM and H3-(1-25) peptide) and with 

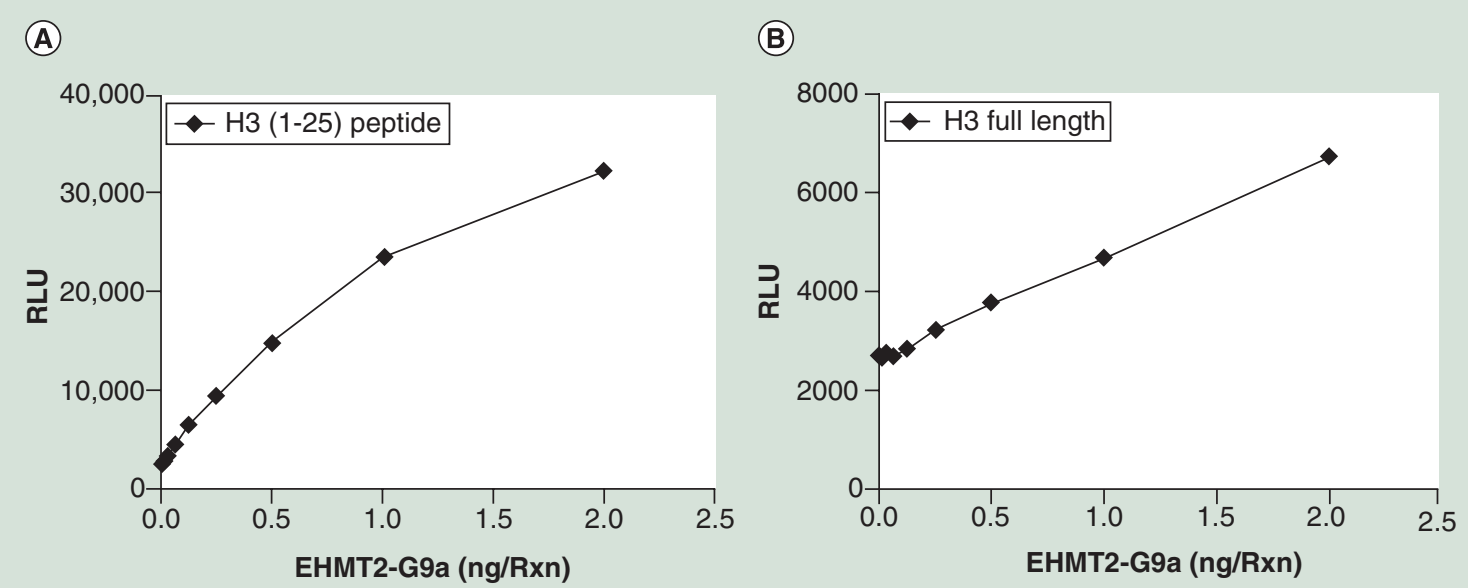

Figure 6. Detection of EHMT2-G9a activity with full length histone H3 or H3-derived peptide as a substrate. Enzyme was diluted to the indicated concentrations with reaction buffer in a solid white low-volume 384-well plate. The reaction was carried out using $1 \mu \mathrm{M}$ S-adenosyl-methionine and $5 \mu \mathrm{M}$ peptide (H3-1-25) (A) or using $5 \mu \mathrm{M}$ full length histone $\mathrm{H} 3(\mathrm{~B})$. All reactions were performed for $60 \mathrm{~min}$ at $23^{\circ} \mathrm{C}$, and processed following the MTase-Glo assay as described under 'Materials \& methods'. Luminescence was measured using the Infinite ${ }^{\circledR}$ M1000 PRO platereading luminometer (Tecan). Data were analyzed using Excel ${ }^{\circledR}$ software and represented as a mean $(n=4)$.

RLU: Relative luminescence unit.

enzyme (1 ng of EHMT2-G9a per well) or without enzyme using MTase-Glo assay. The experiment was performed with 192 replicates for both sets with and without EHMT2-G9a. Similar studies were carried out using the complete enzyme system with and without the inhibitor sinefungin $(100 \mu \mathrm{M})$. MTase-Glo assay was carried out as described above and $\mathrm{Z}$ and Z' factors were calculated according to the formula described in the literature [35].

\section{Compound library screening}

We have tested the assay for the likelihood of generating false hits that are pertinent to the inhibition by assay components. We tested the effect of a library of pharmacologically active compounds (LOPAC) that contains 1280 compounds on SAH detection by MTase-Glo at $10 \mu \mathrm{M}$ final concentrations in 384-well plates in the presence of $1 \mu \mathrm{M}$ SAH. As controls, buffer containing $1 \%$ DMSO was used in the absence or presence of SAH to calculate the 0 and $100 \%$ activity, respectively and to determine the $\%$ interference of the compounds with the assay.

\section{Statistical analysis}

Statistical analysis using either Excel software with determination of the mean \pm standard deviation were used for the figures of SAH titration, SAM titration, etc. and for inhibitor studies to determine the $\mathrm{IC}_{50}$ we used GraphPad Nonlinear regression (curve fit) using sigmoidal dose response (variable slope). For Km determination, we used GraphPad Nonlinear regression (curve fit) using one site binding (hyperbola).

\section{Results}

Methyltransferase-Glo assay principle

The homogenous and bioluminescent MTase-Glo assay is a generic assay, that is, monitor the enzyme activity of any methyltransferase regardless of its substrate acceptor in the presence of the universal methyl donor substrate SAM. Enzymes can be protein methyltransferases, DNA or RNA methyltransferases or small molecule methyltransferases. Also, the acceptor substrate can be small peptide, full length protein, protein complexes such as octameric histones, or nucleosomes, and oligoribonucleotides, oligodeoxynucleotides. In all these cases, the assay detects the universal product $\mathrm{SAH}$ which is converted into Adenosine using SAH hydrolase and the generated adenosine is converted to AMP and ADP using polyphosphate-AMP PAP and AdK. The generated ADP is converted into ATP which is monitored using luciferase/luciferin luminescent reaction. The amount of light produced is proportional to the SAH concentration in the sample and it is correlated with the activity of the methyltransferase (Figure 1).

To determine the assay sensitivity and linearity of light output in relation to enzyme activity we carried out titration of SAH, the universal enzyme reaction product using the methyltransferase Glo (MTase-Glo), and as the results show (Figure 2), there is a linear response with increasing concentrations of $\mathrm{SAH}$ and the assay can detect as low as 20-30 nM of SAH, making it a very desirable assay for high-throughput studies. In order to confirm that the values we obtained using the luminescent SAH detection were reliable, we performed a com- 


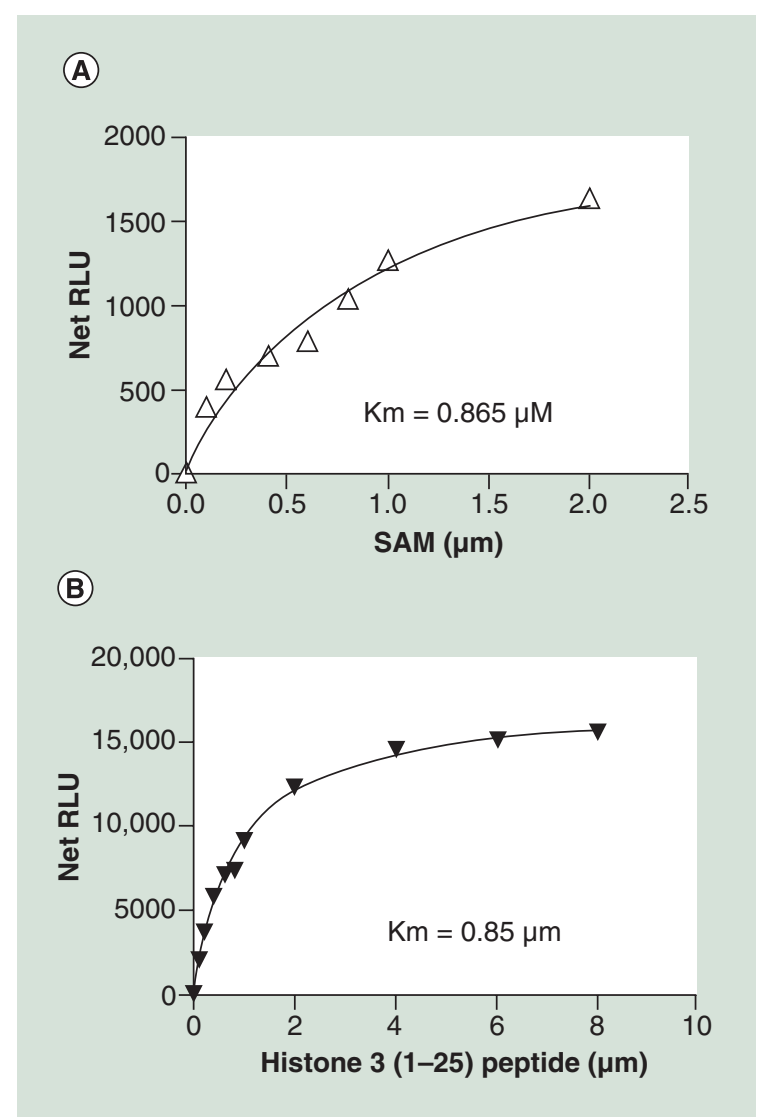

Figure 7. Kinetic analysis of EHMT2-G9a reactions using MTase-Glo assay. Both H3 peptide and SAM substrates were diluted to the indicated concentration with reaction buffer in a solid white low-volume 384-well plate. (A) was carried out using $20 \mu \mathrm{M}$ peptide (H3(1-25) for 5 min reaction at $23^{\circ} \mathrm{C}$, and (B) was carried out using $20 \mu \mathrm{M}$ SAM for $20 \mathrm{~min}$ reaction at $23^{\circ} \mathrm{C}$. The reactions were carried out with $0.25 \mu \mathrm{g} / \mathrm{ml}$ of EHMT2G9a, then trifluoroacetic acid was added to stop enzyme reaction, followed by MTase-Glo assay (twostep protocol). Both panels were processed as described in the MTase-Glo ${ }^{\mathrm{TM}}$ assay under 'Materials \& methods'. Luminescence was measured using the Infinite ${ }^{\circledR}$ M1000 PRO plate-reading luminometer (Tecan). Data were analyzed using GraphPad Prism program 6.03 software using Micahelis-Menten equation.

$\mathrm{Km}$ : Numerically equivalent to the substrate concentration that yields half-maximal velocity $\mathrm{V}_{\max }$; RLU: Relative luminescence unit; SAM: S-adenosyl-methionine.

parison with direct measurement of SAH using HPLC method, and we got similar results to those obtained by the luminescence method, as shown in Figure 3. This supports the notion that the activity obtained using the MTase-Glo and HPLC are very similar.

High quality of the SAM substrate is important for enhanced assay sensitivity

In order to rule out any interference from the components of the methyltransferase reaction, we also show that the universal SAM substrate does not produce light unless methyltransferase enzyme and its other substrate are present in the reaction (absolute requirement for the methyltransferase) while the product $\mathrm{SAH}$ is converted into light output in the presence or absence of methyltransferase (methyltransferase independent) Figure 4A. This is very critical for obtaining low background and sensitive assay. In addition, we show that the SAM substrate used in the assay is free of SAH contamination as the light output signal and the linearity of the assay do not change when SAM at 1 or $10 \mu \mathrm{M}$ is included with the detected $\mathrm{SAH}$ (Figure 4B), a point that is worth consideration when running a screen for methyltransferases. Most of the commercially available SAM substrates are contaminated with high level of SAH and thus increase the background and decrease the sensitivity of the assay. To address this issue, we carried out studies using our highly purified SAM and compared it with SAM purchased from commercially available sources. It is apparent that addition of purified SAM used in this new assay has minimal effect on luminescence reading of SAH indicating high purity of SAM since it is not directly detected by the assay unless it is converted to SAH by the enzyme. In contrast, SAM from other suppliers show high percentage of SAH contamination resulting in high background signal in the absence of enzyme (5-10-fold higher background than the SAM available from Promega (Figure 4C \& D).

\section{A simple assay protocol shortens assay time}

An important question that we wanted to address during the development of this assay is whether it can be carried out in two-step or one-step where the methyltransferase reaction would be run simultaneously in the presence of the first MTase-Glo reagent and then the MTase-Glo detection solution will be added to generate light (one step) or alternatively terminate the methyltransferase reaction first using TFA before the addition of the MTase-Glo reagent followed by the addition of the MTase-Glo detection solution (two step). Toward this goal we carried out methyltransferase reactions using DOT1L enzyme either in one-, or two-step assay using mono/dinucleosome as substrate and SAM as co-substrate. As shown in Figure 5A, the total RLU generated using a one-step or two-step assays are similar indicating that the MTase-Glo reagent does not interfere with the methyltransferase reaction and can be included during the SAH production step. As a corollary, this experimental results demonstrate that there is no need to terminate the reaction with TFA if the assay is performed in one step as the MTase-Glo detection solution stops the reaction. Therefore, the MTase-Glo assay can be carried out in one-step sim- 
plifying and shortening the time required to complete the assay.

\section{MTase-Glo is a universal methyltransferase activity detection assay}

Having established that the assay can only detect the SAH product only when the enzyme used SAM as substrate, we then determined the activity of several classes of methyltransferases; these include lysine methyltransferases, arginine methyltransferases and DNA methyltransferases to ensure the universality of the assay. Furthermore to prove that the assay can be used with several substrates with varying chemical structures, we also tested the activity of these enzymes using small peptides, large histone proteins, core histones, nucleosomes and oligodeoxynucleotides.

We first tested EHMT2 (G9a) as a representative of the class of protein lysine methyltransferases using SAM as substrate and either the $\mathrm{H} 3$ peptide (1-25) or full length $\mathrm{H} 3$ protein. It is apparent from Figure 6 that the enzyme is capable of using both substrates but it prefers the peptide over full length $\mathrm{H} 3$ as substrate by about five-fold. It is also apparent that the assay is sensitive enough to detect the activity of as low as $1 \mathrm{ng}$ or less of the enzyme.

We carried out further kinetic studies on G9a using MTase-Glo by varying the substrate concentrations of SAM and keeping the other substrate constant (peptide), and varying the peptide concentration but keeping SAM concentration constant. We were able to show that the enzyme activity increases with increasing SAM substrate concentration (Figure 7A), and also an increase in enzyme activity as indicated by increase in light output with increasing the peptide substrate concentrations (Figure 7B). The figures show a hyperbolic kinetic profile with a $\mathrm{Km}$ value of $0.87 \mu \mathrm{M}$ and $0.86 \mu \mathrm{M}$ for SAM and H3-(1-25) peptide substrate for G9a, respectively. These values are in accord with those published in the literature for this enzyme with these substrates and thus demonstrating that the assay is generating kinetic values that are reliable [25].

Other lysine methyltransferases were also tested using peptides derived from histone proteins ( $\mathrm{H} 3$ and $\mathrm{H} 4$ ), full length histone proteins and octameric form of histones. We used EZH1 and EZH2 as the enzymes for demonstration. As shown in Figure 8, we were able to demonstrate that MTase-Glo can be used to monitor the activity of these enzymes at low concentrations, with variable preference for the substrates used. It is noteworthy that EZH1 and EZH2 prefer full length $\mathrm{H} 3$ as a substrate better than $\mathrm{H} 3$-derived peptide or core histone octamers.

Since nucleosomes are considered to be the native substrate in chromatins, we tested the assay performance using DOT1L as the enzyme and various forms of substrates using MTase Glo. As shown in Figure 9,
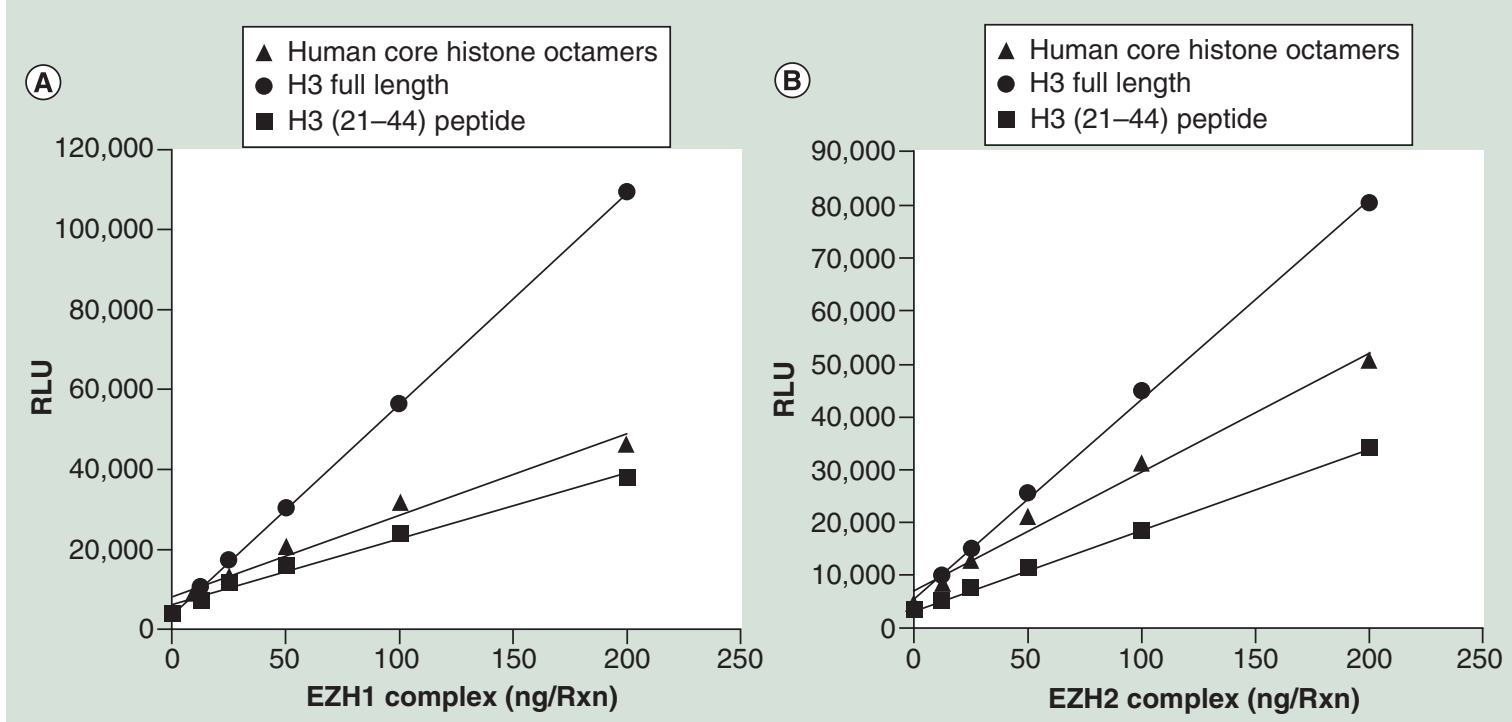

Figure 8. Detection of the activity of EZH1 and EZH2 complexes with peptide, full length protein and core histone octamers as substrates using MTase-Glo assay. Both EZH1 complex (A) and EZH2 complex (B) were diluted to the indicated concentrations with reaction buffer in a solid white low-volume 384-well plate. Both enzymes reactions were carried out at $10 \mu \mathrm{M} \mathrm{S}$-adenosyl-methionine and either $20 \mu \mathrm{M}$ of H-3, H3-(21-44) or $0.1 \mathrm{mg} / \mathrm{ml}$ of human core histones octamers. All reactions were run for $60 \mathrm{~min}$ at $23^{\circ} \mathrm{C}$, and processed following the MTase-Glo assay protocol as described under 'Materials \& methods'. Luminescence was measured using the Infinite ${ }^{\circledR}$ M1000 PRO plate-reading luminometer (Tecan). Data were analyzed using Excel ${ }^{\circledR}$ software and represented as mean $(n=4)$. RLU: Relative luminescence unit. 


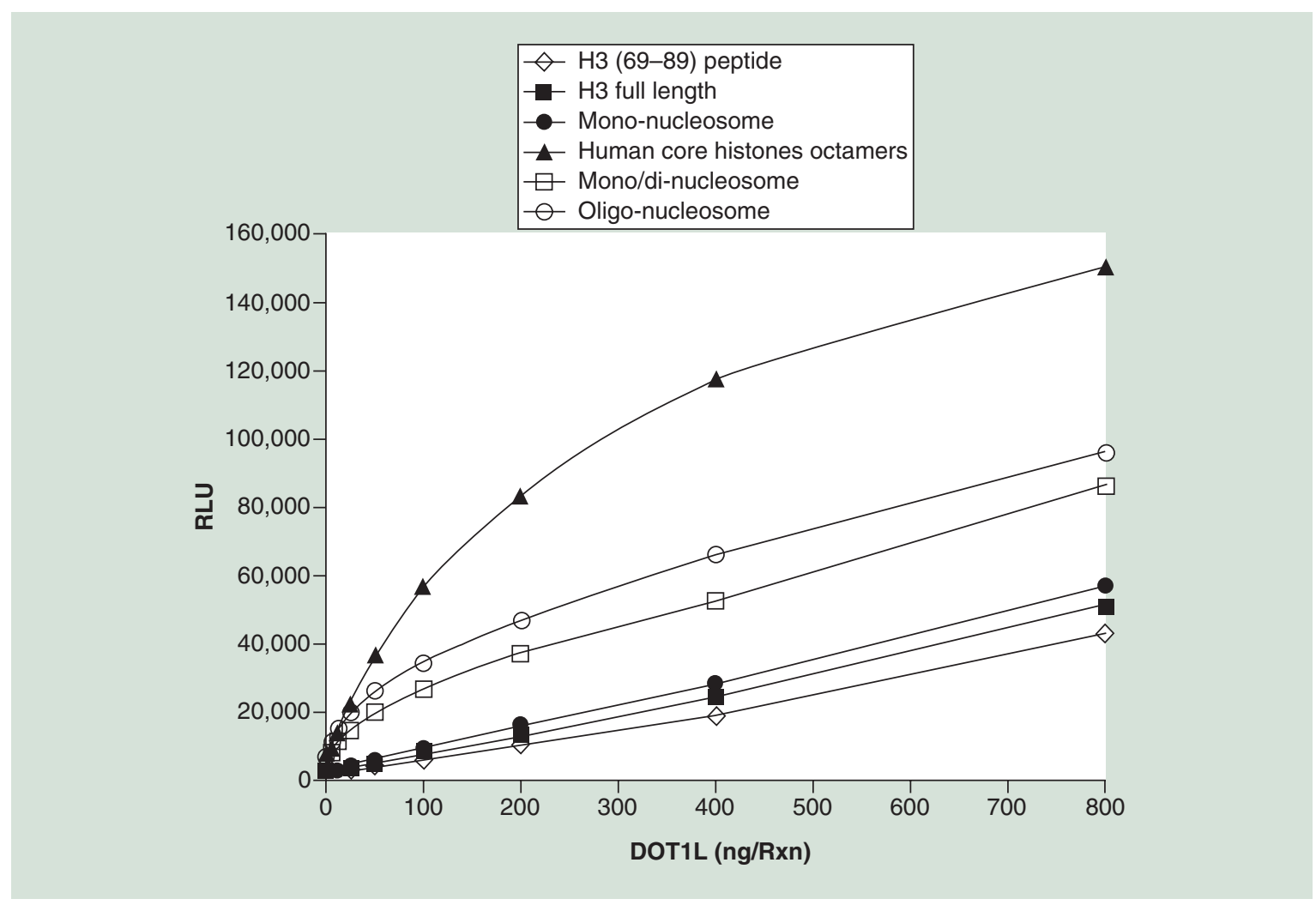

Figure 9. Evaluation of different potential high structure substrates for DOT1L methyltransferase using MTase-Glo assay. DOT1L was diluted to the indicated concentrations with reaction buffer in a solid white low-volume 384-well plate. The enzyme reactions were carried out at $10 \mu \mathrm{M} \mathrm{S}$-adenosyl-methionine and either $20 \mu \mathrm{M} \mathrm{H} 3(69-89)$ peptide, $20 \mu \mathrm{M}$ full length H3, $0.25 \mathrm{mg} / \mathrm{ml}$ of human core histones octamers, $0.25 \mathrm{mg} / \mathrm{ml}$ of mononucleosome, $0.25 \mathrm{mg} / \mathrm{ml} \mathrm{mono} / \mathrm{di}$-nucleosome or $0.25 \mathrm{mg} / \mathrm{ml}$ oligonucleosome. Reactions were carried out for $60 \mathrm{~min}$ at $23^{\circ} \mathrm{C}$ in a one-step protocol and processed as described under 'Materials \& methods'. Luminescence was measured using the Infinite ${ }^{\circledR}$ M1000 PRO plate-reading luminometer (Tecan). Data were analyzed using Excel $^{\circledR}$ software and represented as mean \pm standard error $(n=4)$.

RLU: Relative luminescence unit.

DOT1L can methylate peptides, full lengthy histones, human core histones, mononucleosomes, mono/Di nucleosomes and oligonucleosomes. It is interesting to note that the enzyme prefers higher order protein structure as substrates such as core histones and oligonucleosomes. Earlier studies using binding and isothermal titration calorimetry assays showed that DOT1L has very high affinity toward nucleosomes as substrate $(\mathrm{Kd}=14 \mathrm{nM})$ [36]. Thus, the assay can be used to monitor the activity of methyltransferases with any substrate that is used by the enzyme regardless of their structural complexity. It should be noted that the use of nucleosomes or full length histone proteins as substrate may increase slightly the background in our assay as observed in Figures 5, 6, 8 \& 9 since we use them as is when purchased. Therefore, a need for dialysis to remove any extraneous components that might cause the increase in background observed when there is no enzyme may be helpful. To show that the linearity of the enzyme activity is maintained, we plotted the net RLU after subtracting the background as shown in Figure 5B as an example.
Monitoring enzyme activity of protein arginine methyltransferases

Another important feature of this assay is its utility to monitor the activity of methyltransferases that methylate arginine residues in peptides and full length proteins. For this application we used protein arginine methyltransferase 1, 4 and 5 (PRMT1, 4 and 5) and full length histones or histone-derived peptides as substrates. The results in Figure 10A \& B show that the activity of these enzymes can be monitored using this assay with minimal amount of the enzymes used. Again, the assay can be used to monitor the activity of these arginine methyltransferases using full length protein substrates or peptides derived from these proteins.

\section{Monitoring enzyme activity of DNA methyltransferases}

To prove the universality of the assay in not only utilizing proteinacous substrates but also can be used to monitor the activity of enzymes that methylate nucleic acids. Toward this goal, we tested the assay using DNA 
(C)

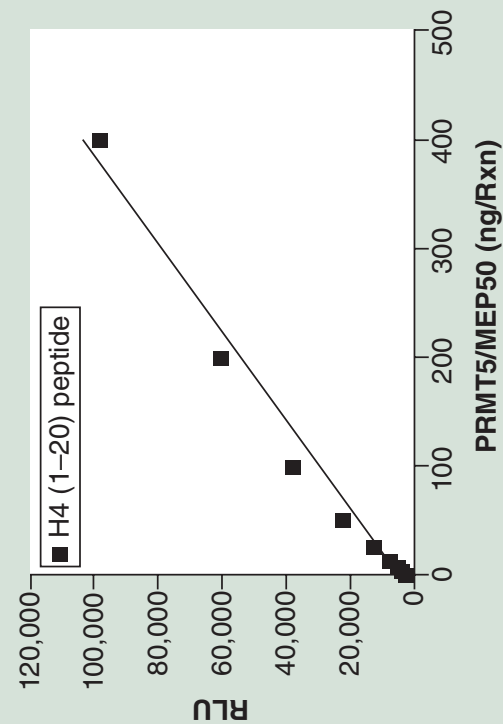

(4)
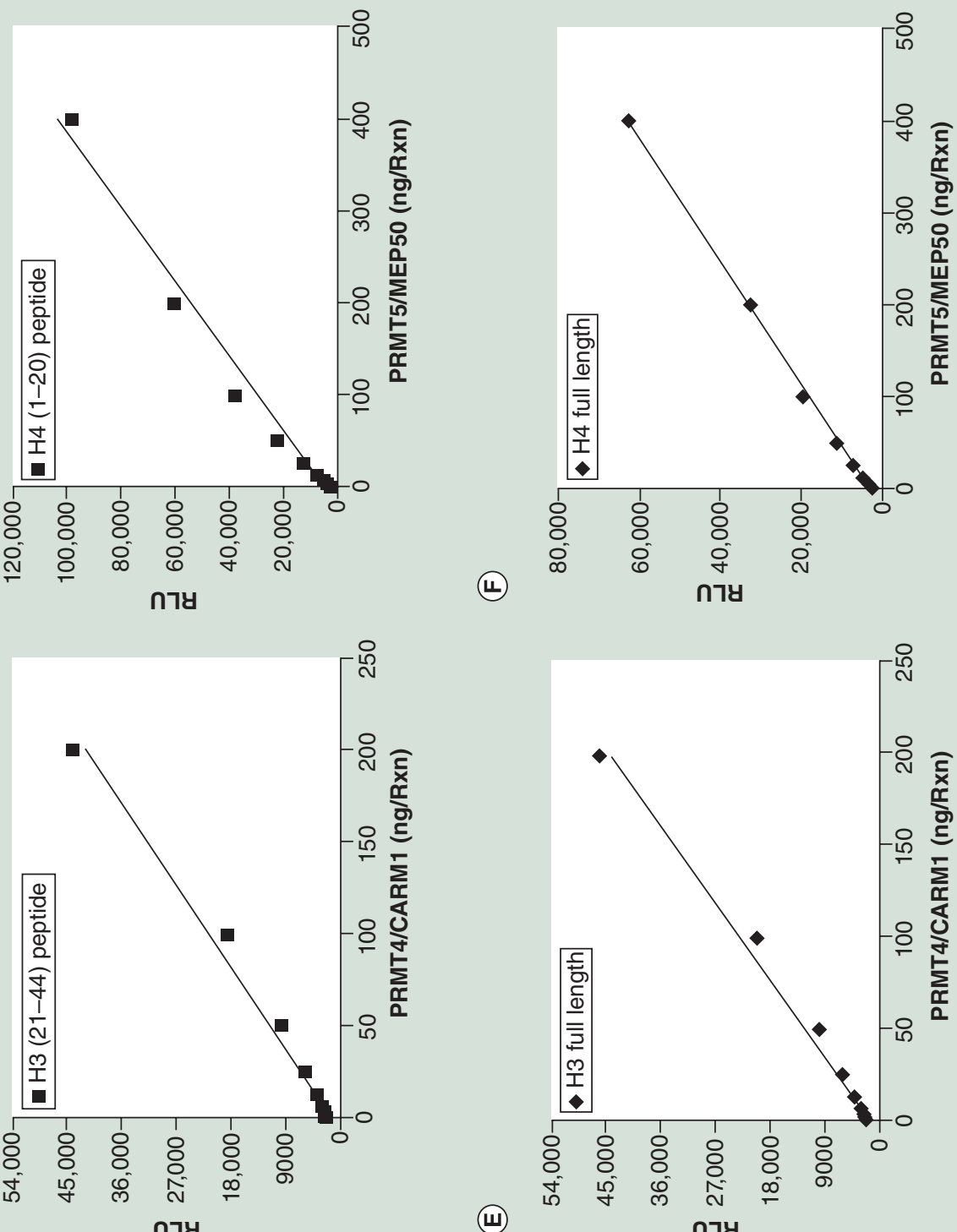

(i)

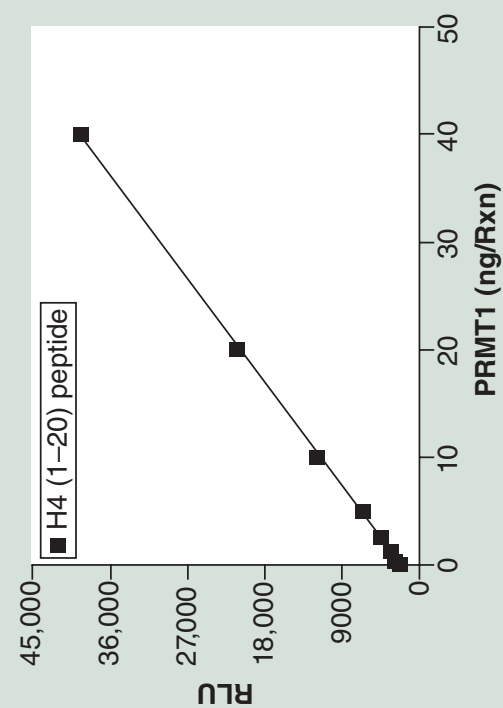

(14)
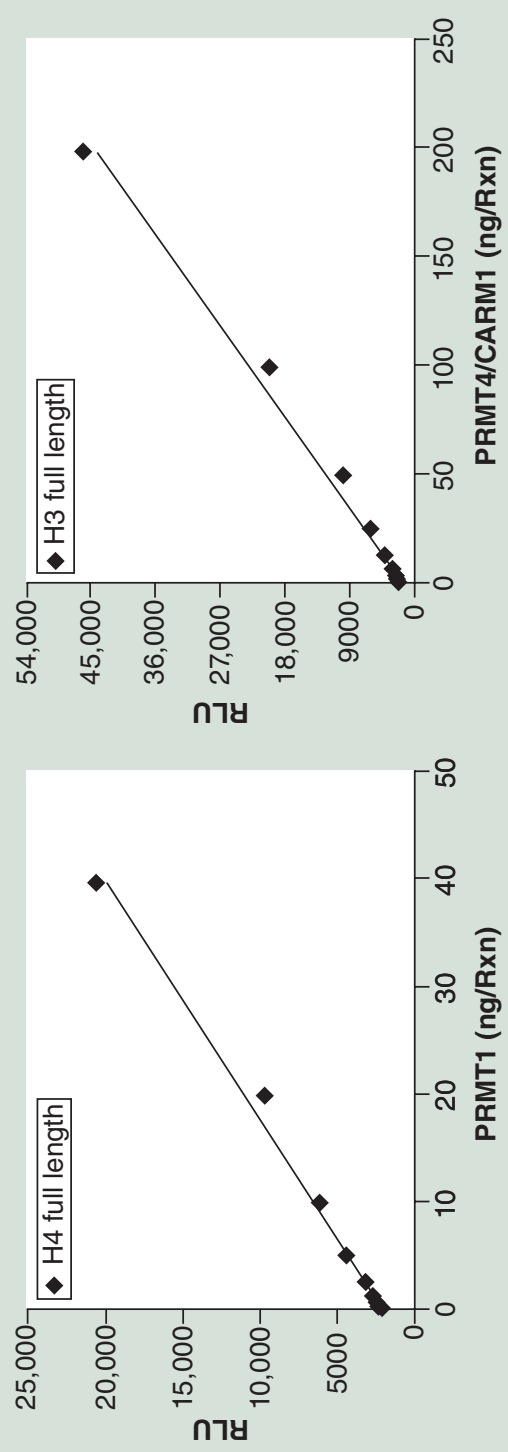

จำ

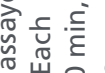
屯े

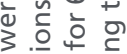

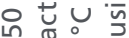

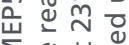
$\sum_{i n j}$ 点. $\cong$ ว

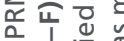
은 온 क人 $x$ 产

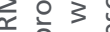
중

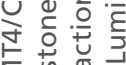

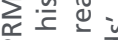
荡市 过 政 安

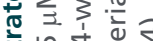

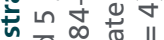

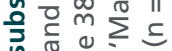

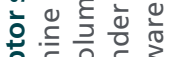

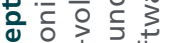

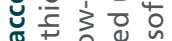

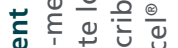
के

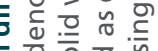

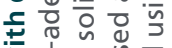
ऊं宀

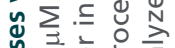

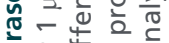

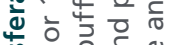

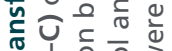

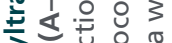

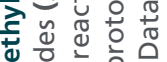

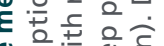
这告要

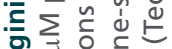
约居就

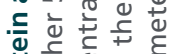

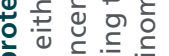
훙웡ㅎㅁ $>0$ व

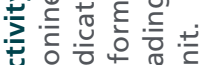

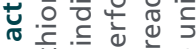

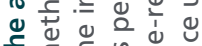

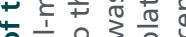
ธ

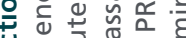
후응 山ें 둥응 . $\sum^{0} \sum^{0} \dot{d} \sum$ 을

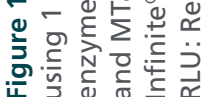


(A)

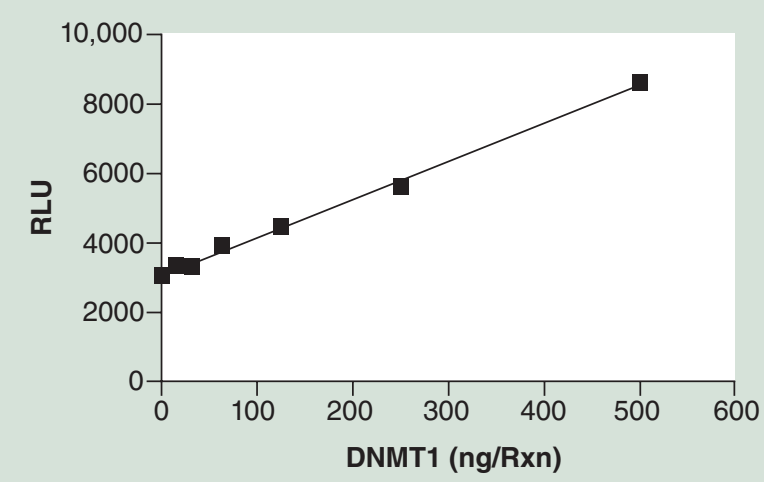

(B)

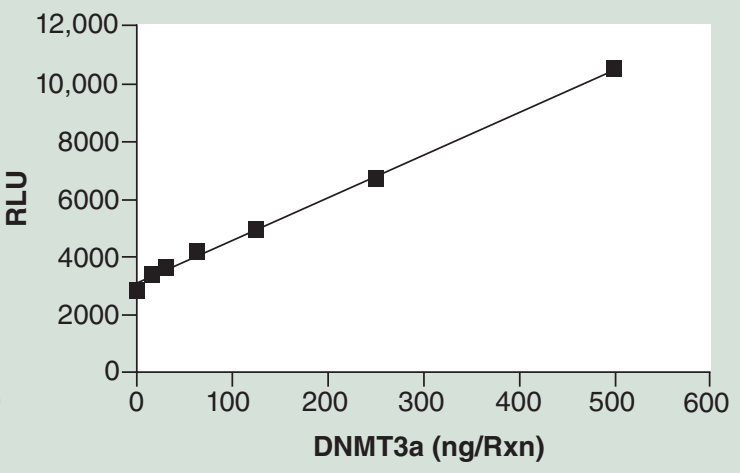

Figure 11. Detection of DNA methyltransferase DNMT1 and DNMT3a activities using the MTase-Glo assay.

Enzymes were diluted to the indicated concentrations with reaction buffer and in the presence of $10 \mu \mathrm{M}$ S-adenosyl-methionine and $20 \mathrm{nM}$ double stranded Oligo DNA. Reactions were carried out at $37^{\circ} \mathrm{C}$ for $90 \mathrm{~min}$ in a solid white low-volume 384-well plate. The assay was performed as described in section 'Materials \& methods' using a one-step protocol. Each data point represents the average of two replicates. Luminescence was measured using the Infinite ${ }^{\circledR}$ M1000 PRO plate-reading luminometer (Tecan). Data were analyzed using Excel ${ }^{\circledR}$ software. RLU: Relative luminescence unit.

methyltransferases (DNAMT1, 3a). As shown in Figure 11, the activity of these enzymes can be monitored using this assay and the amount of enzymes needed is relatively in the nanogram level making it ideal also for screening for enzyme modulators. It is noteworthy that the use of a negative control DNA such as DNA with no CG motifs or GC instead of CG motif is warranted to ensure the robustness of the assay.

\section{Testing methyltransferase modulators}

To demonstrate the use of the assay in detecting the activity of potential modulators of methyltransferases we applied it not only to a screening of a library of a small molecules, but also in determining the mechanism of action of inhibitors and generating kinetic values that are in accord with literature. We first carried out inhibitor titration using the previously reported EZH2 inhibitor GSK126 and show that this compound is a competitive inhibitor toward SAM substrate with $\mathrm{IC}_{50}$ decreasing with decreasing SAM concentrations with $\mathrm{IC}_{50} \mathrm{~s}$ of $3.26 \mathrm{nM}$ and $6.68 \mathrm{nM}$ obtained at $0.5 \mu \mathrm{M}$ and $5 \mu \mathrm{M}$ SAM concentrations, respectively (Figure 12A). The reported value for $\mathrm{IC}_{50}$ of the compound is $0.5-3 \mathrm{nM}[37,38]$, thus validating its use to study the mode of action of methyltransferase inhibitors.

Similarly, we also demonstrated the inhibition and mode of action of the inhibitor sinefungin toward G9a using MTase-Glo detection. We have titrated the inhibitor in the presence of two different concentrations of SAM ( 2 and $10 \mu \mathrm{M})$. As shown in Figure 12B, the inhibitor inhibited the enzyme activity with $\mathrm{IC}_{50}$ of $36 \mu \mathrm{M}$ and that its enzyme inhibition was competed for by increasing SAM concentration where the $\mathrm{IC}_{50}$ was $68.62 \mu \mathrm{M}$ at $10 \mu \mathrm{M}$ SAM. These $\mathrm{IC}_{50}$ values are in accord with previously reported values [39]. It will be desirable to check the potency and selectivity of several inhibitors against the enzymes of interest to ensure the robustness of the data generated using this assay.

\section{Testing assay robustness}

The reproducibility of the assay is determined by the value $Z^{\prime}$ which is defined as follows:

$$
Z^{\prime}={ }_{1}-\left(3 \sigma_{\text {sample }}+3 \sigma_{\text {control }} / \mu_{\text {sample }}-\mu_{\text {control }}\right)
$$

Where $\sigma$ is the SD, and $\mu$ is the mean. A value of $Z^{\prime}$ of over 0.5 indicates excellent and robust assay (see [35] for more details). We have generated three $\mathrm{Z}$ values to ensure the robustness of the assay, these include: titration of the product $\mathrm{SAH}$ alone (with and without SAM); complete enzyme reaction which include enzyme, SAM and substrate; and complete enzyme system (with and without inhibitor).

The first was carried out in sixteen 384-well plates, each containing wells with and without SAH alone. This means eight plates containing SAH and eight plates that do not have $\mathrm{SAH}$, that is 3072 replicates for each treatment. A Z' value of 0.8 and CV of under $5 \%$ were obtained which attests to the robustness of the assay (Figure 13A).

The second was carried out using 384 wells to test for robustness of the system which also contains enzyme and SAM versus enzyme without SAM. The 
data generated from this experiment gave a Z' value of 0.84 (Figure 13B).

The third was carried out using complete enzyme system but with and without enzyme inhibitor using 192 wells and we obtained a Z' value of 0.71 (Figure 13C).

We conclude that the data generated attest to the high quality of the assay in not just being robust for obtaining reliable assay performance with and without enzyme, but also giving a great robustness and reliability for experiments carried out in the presence and absence of inhibitors. These results also ensures assay readiness for high-throughput screening (HTS) research.

\section{Testing for compounds that may affect assay} performance by generating false hits

Finally, because this assay will be used for small molecule compounds screening, it is important to check its quality regarding the generation of false hits during a screening project using chemical libraries. Toward this goal we used a LOPAC which contains 1280 of clinically relevant compounds used at $10 \mu \mathrm{M}$ final concentrations. The LOPAC has been routinely used by the HTS scientific community when developing a new assay to test for false hits that may be due to an interference of the library compounds with the assay components. Therefore, we followed a common practice that is well agreed to by many programs engaged in HTS research to test our assay against the library compounds in order to find out whether any of the compounds affect the assay format by generating false hits due to interference with assay performance. We realize that investigators who are searching for new enzyme modulators and potential therapeutic agent may have their own customized libraries that carry the desired scaffolds for the potential modulator. The results shown with LOPAC is just an example to show that the assay shows robustness with this library. Further testing will be done by the investigators using their own libraries.

As sown in Figure 14, it is apparent that two compounds were found to inhibit the assay by about $40 \%$ (butaclamol and 6-Me-2-(phenylazo) 3-pyridinol and one inhibited by over 90\% Ap4A. The compound Ap4A is known to be a potent luciferase inhibitor, and require retesting using the same assay but without the methyltransferase to identify those compounds that directly inhibit luciferase, or use an orthogonal assay. The other two compounds gave a positive response, that is, indicating activation and not inhibition. This was expected since these compounds were identified as adenosine or adenosine derivatives (adenosine and N6-methyladenosine), which gave $30-40 \%$ increase in signal. Thus a false hit ratio of less than $0.5 \%$ indicating not only a robust assay $\left(Z^{\prime}>0.8\right)$ but also lower false hits minimizing the effort for rescreening the hits generated in the primary screen using this assay.

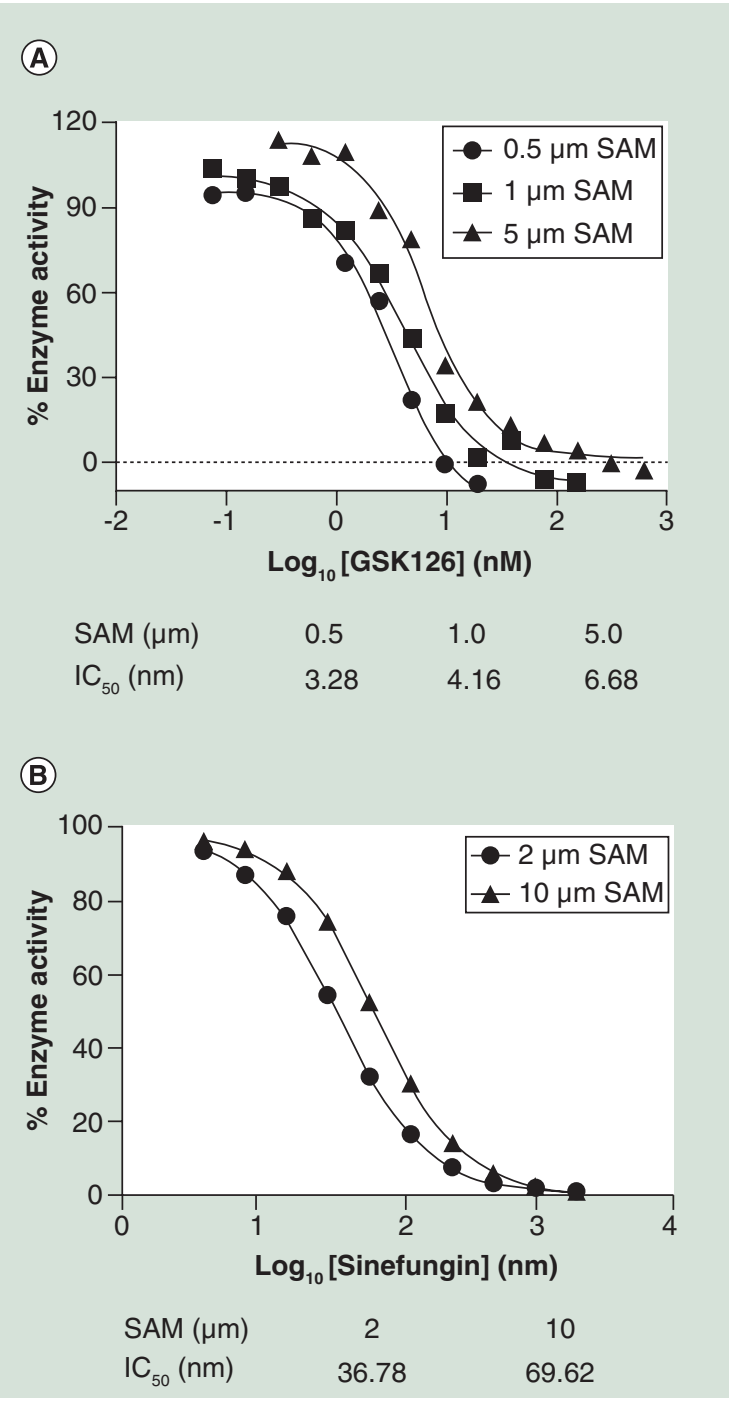

Figure 12. Detection of methyltransferase inhibitor effect and mode of action using the MTase-Glo assay. For determining the $\mathrm{IC}_{50}$ value of GSK126 for EZH2 complex (A), reactions were assembled with $0.5 \mu \mathrm{g}$ of EZH2 enzyme, $0.5,1$ or $5 \mu \mathrm{M}$ SAM with $10 \mu \mathrm{M}$ H3 protein and the indicated concentrations of GSK126. Reactions were incubated for $60 \mathrm{~min}$ at $30^{\circ} \mathrm{C}$. For determining the $I C_{50}$ value of sinefungin toward EHMT2-G9a (B), reactions were assembled with $1 \mathrm{ng}$ of EHMT2-G9a per reaction with $2 \mu \mathrm{M}$ or $10 \mu \mathrm{M}$ SAM, $50 \mu \mathrm{M} \mathrm{H} 3(1-25)$ peptide and indicated concentrations of sinefungin. Reactions were incubated for $60 \mathrm{~min}$ at $23^{\circ} \mathrm{C}$. Reactions were carried out in a solid white lowvolume 384-well plate and processed using MTase-Glo assay as described in 'Materials \& methods'. Each data point represents the average of two replicates. Data analysis was performed using Exce $^{\circledR}$ software and GraphPad Prism 6.03.

SAM: S-adenosyl-methionine. 
When testing different compounds effect on the assay, we always use DMSO as a vehicle up to $5 \%$. This concentration has no effect on the Methyltransferase-Glo reagents (data not shown).

\section{Discussion}

Epigenomics research has witnessed an intense activity and strong interest in the last few decades and the clinical relevance of this research has resulted in the

(A)

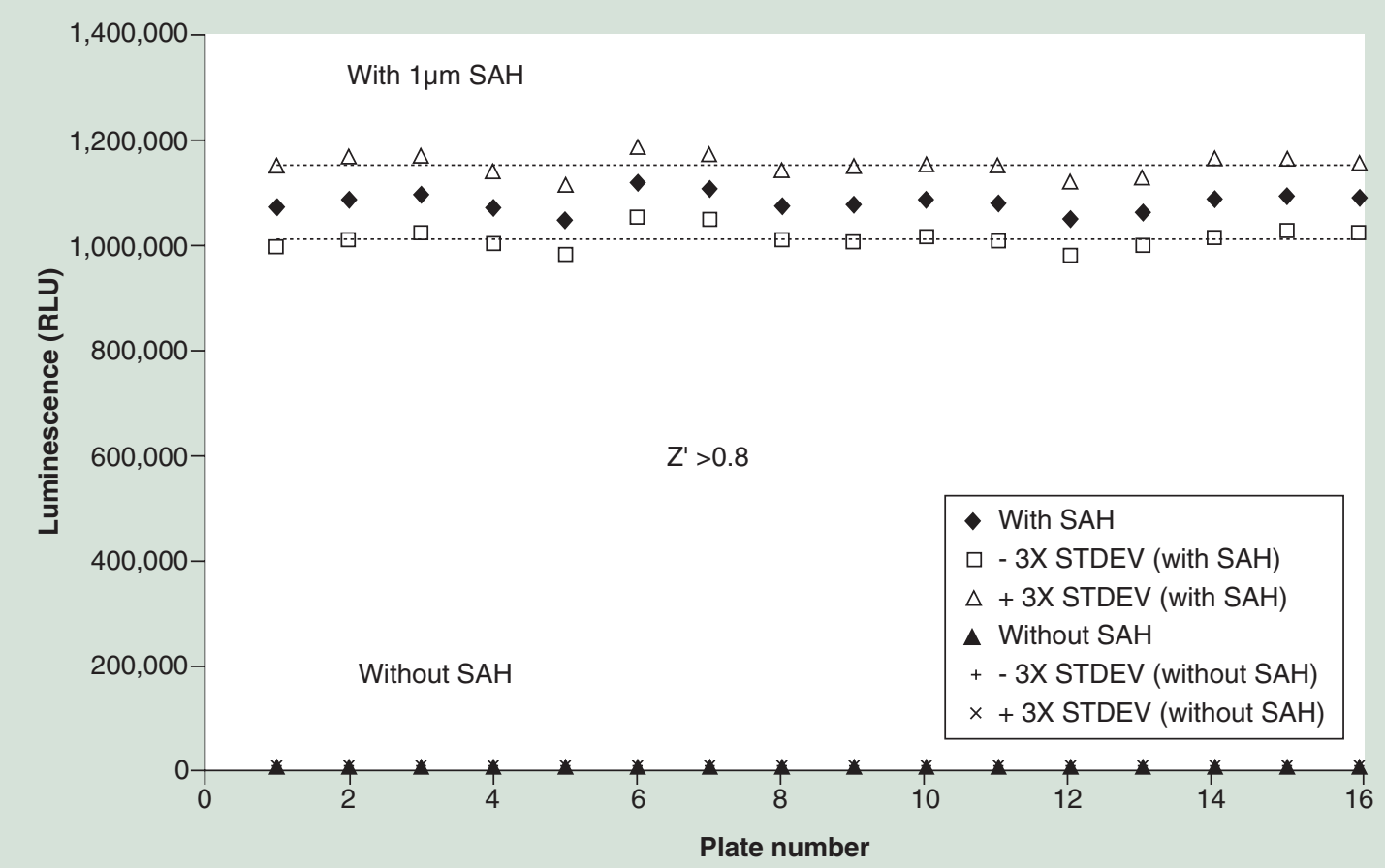

(B)

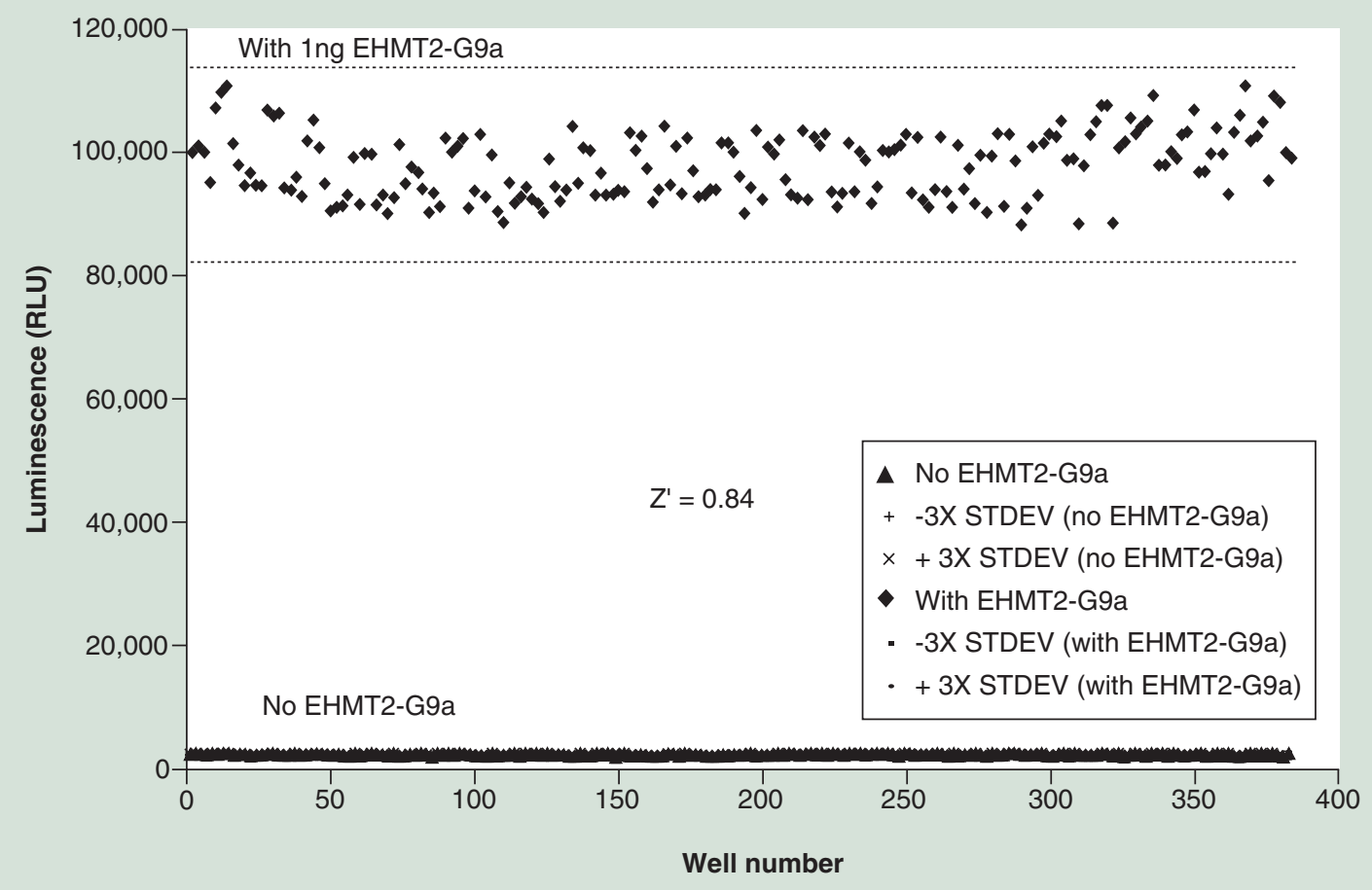


(C)

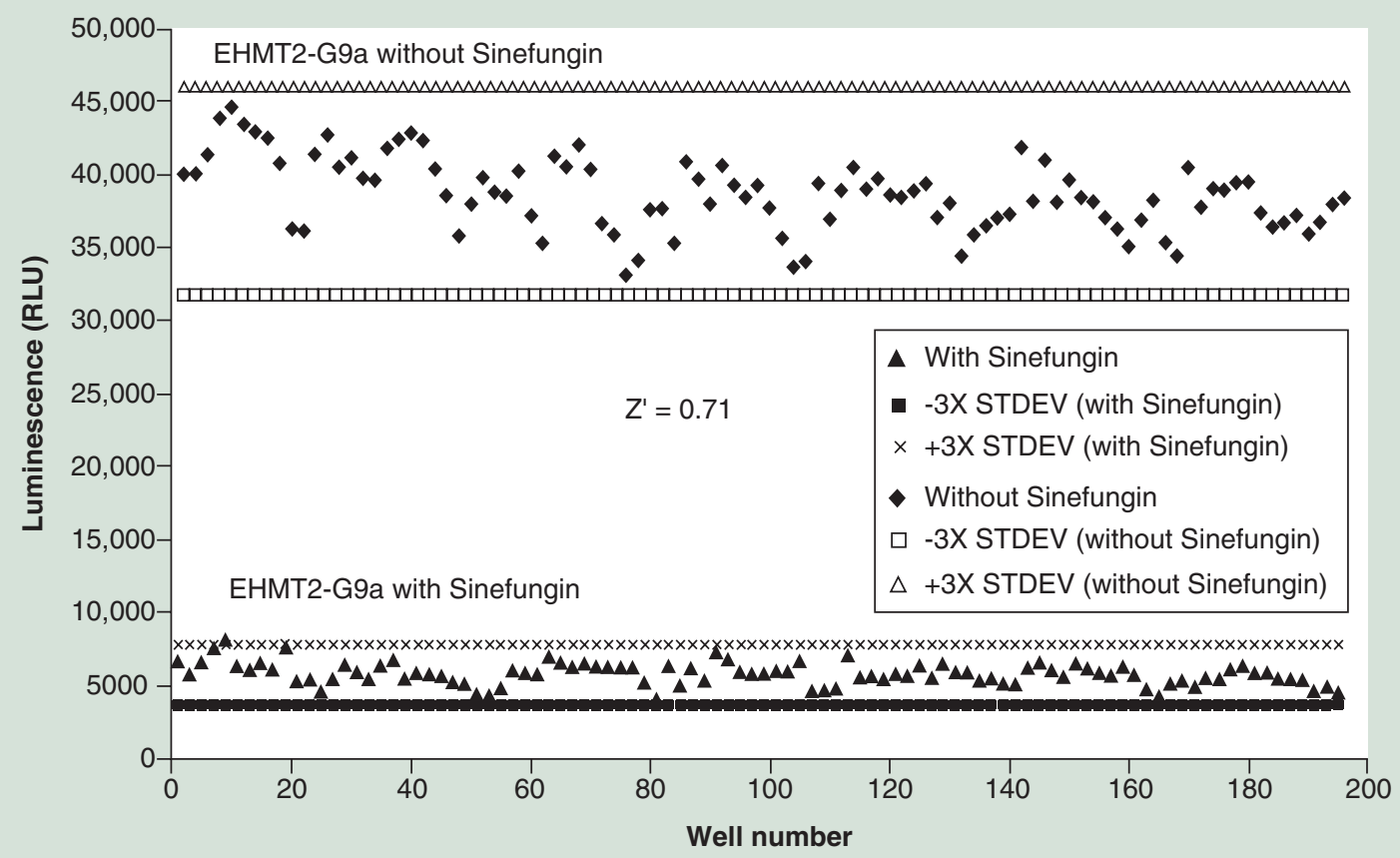

Figure 13. Determination of the robustness of the MTase-Glo'M assay for high-throughput screening (see facing page). (A) SAH detection Z' value was generated using 16 different solid white low-volume 384-well plates with or without $1 \mu \mathrm{M}$ SAH added to each well of the plates and detected with MTase-Glo assay. The average luminescence and signal to background values from each plate are reported and the $Z^{\prime}$ value was calculated based on the published equation [35]. (B) Methyltransferase-generated SAH detection Z' value was generated by using MTase-Glo reagents with and without $1 \mathrm{ng}$ of EHMT2-G9a per reaction and $10 \mu \mathrm{M}$ S-adenosyl-methionine and 10 $\mu \mathrm{M}$ H3 (1-25) peptide for $60 \mathrm{~min}$ at $23^{\circ} \mathrm{C}$ in a solid white low-volume 384-well plates. (C) Z factor value was generated by using MTase-Glo reagents with and without sinefungin $(100 \mu \mathrm{M})$ in $1 \mathrm{ng}$ of EHMT2-G9a per reaction for $60 \mathrm{~min}$ at $23^{\circ} \mathrm{C}$ with $1 \mu \mathrm{M}$ S-adenosyl-methionine and $5 \mu \mathrm{M} \mathrm{H3}$ (1-25) peptide in a solid white low-volume 384-well plates. The assay was performed as described in 'Materials \& methods' using a one-step protocol. Luminescence was measured using the Infinite ${ }^{\circledR}$ M1000 PRO plate-reading luminometer (Tecan). Data were analyzed using Excel ${ }^{\circledR}$ software.

RLU: Relative luminescence unit; SAH: S-adenosyl-homocysteine; STDEV: Standard deviation.

US FDA approval of drugs targeting DNA methylation and histone deacetylation [1]. Most recently, the areas of protein methylation and demethylation have been actively pursued by both academic and pharmaceutical research. The success of such endeavor is predicated on the availability of robust assays to monitor the activity of these enzymes. Such assays need not only to be robust, but also homogenous and amenable to high-throughput format. A desirable feature of the current assay is its universality so that it can be used to monitor the activity of as many diverse methyltransferases with a variety of substrates varying in their chemical structure, such as peptides, proteins, nucleic acids, small molecules, etc.

To address all these needs, the homogenous MTaseGlo assay described here is based on luminescent readout and offers features such as low false hit generation that are known to occur when fluorescence-based assays are used and can reach in some cases as high as $60 \%$ [29]. In fact, a recent report using AlphaLISA method as a screening tool found similarly high false hits and used MTase Glo as an orthogonal assay to correct for those false hits [40]. Additional concern with those assays that can only use peptide substrates and not full length proteins, protein complexes or nucleosomes since they rely mainly on the use of antibodies and even with small peptides, the amount of antibody and beads required have to be optimized to get reliable signal. The assay we describe here is homogenous, a two-step add and read after completion of the methyltransferase reaction, and is sensitive enough so low amounts of enzyme is needed for an HTS campaign.

Our assay relies on the detection of the universal methyltransferase reaction product SAH by converting it to adenosine via the use of SAH hydrolase, the generated adenosine is then converted to AMP followed by 


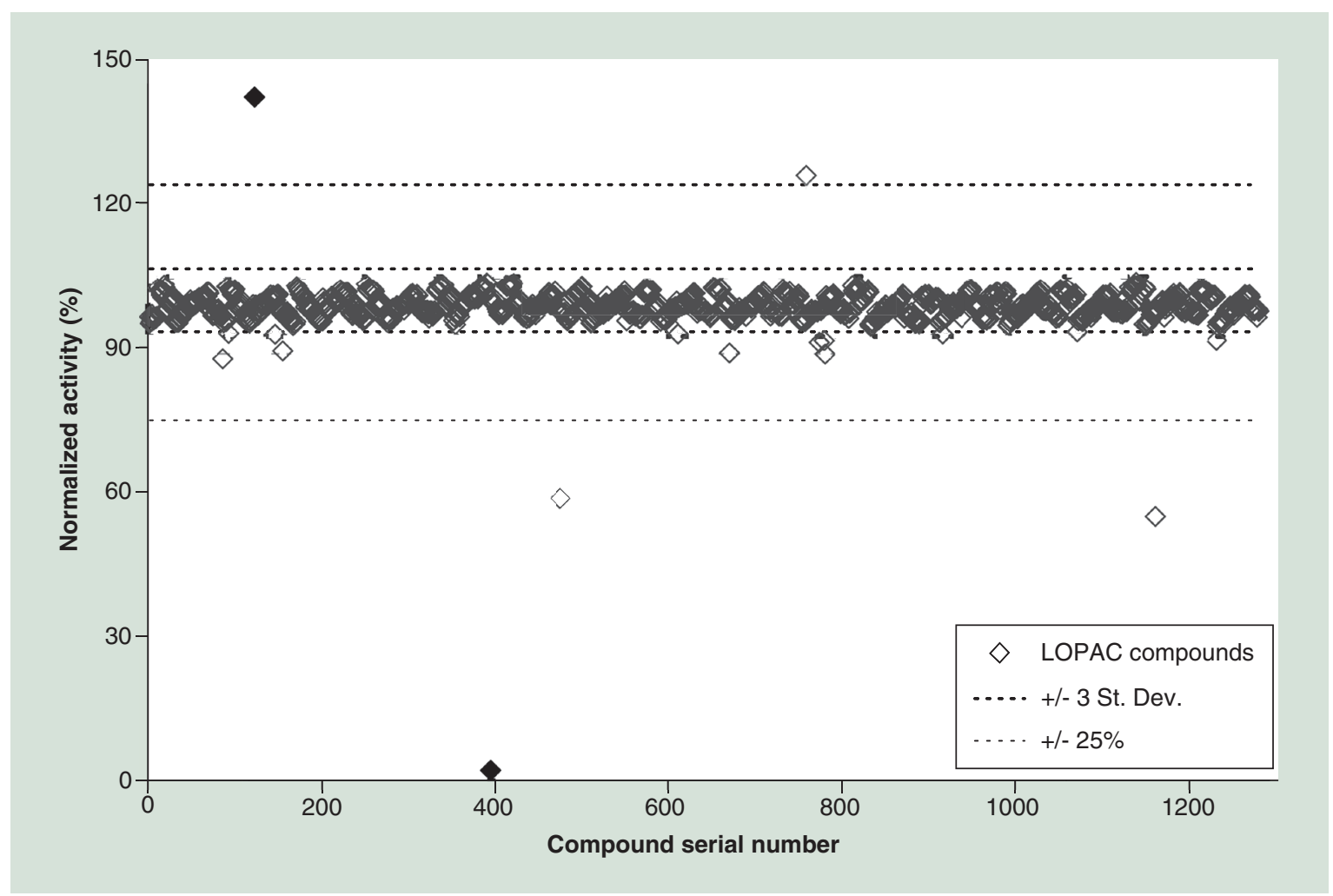

Figure 14. Screening for potential inhibitors of MTase-Glo'M reagents using LOPAC library. The compounds (1280) were tested using 16 plates, 80 compounds per plate, performed at $23^{\circ} \mathrm{C}$ for $60 \mathrm{~min}$ as described in 'Materials \& methods' in solid white flat-bottom low-volume 384-well plates. S-adenosyl-homocysteine concentration was $1 \mu \mathrm{M}$ in methyltransferase reaction buffer and final concentrations of $10 \mu \mathrm{M}$ of each compound and $1 \%$ dimethyl sulfoxide. Open square represent wells containing library compounds. Dotted lines indicate \pm 3 standard deviations of these populations. Only one compound interfered with the assay by causing over $90 \%$ inhibition and it is a known inhibitor of luciferase (Ap4A) while two more inhibited the assay by less than $50 \%$. In addition, there were two adenosine derivatives that resulted in stimulation by less than $50 \%$.

St.Dev.: Standard deviation; LOPAC: Library of pharmacologically active coumpounds.

the later conversion to ADP and then to ATP using sequential reactions in one step and then ATP is converted to light output using luciferase reaction. The signal generated is proportional to the amount of SAH generated from the methyltransferase reaction. Previously, Hemeon et al. [32] and Ibanez et al. [33] reported a methyltransferase assay where they used a different enzyme PPDK to convert AMP to ATP while ours uses the two sequential enzyme reactions using PAP and PK to ensure full conversion of AMP to ATP. Also, the luciferase used in those assays is recombinant firefly luciferase enzyme which generates unstable signal (flash signal) and not steady signal which is undesirable feature for batch processing in HTS programs. Others [31] used Adk to convert adenosine to AMP and monitoring the decrease in ATP concentration that is used as substrate for Adk to generate luminescence using Kinase $\mathrm{Glo}^{\circledR}$ detection protocol from Promega which was designed for kinase assay based on ATP depletion by active kinases. Thus the generated signal is a decreasing signal (ATP depletion) which is less sensitive to small changes in methyltransferase activity and thus has lower sensitivity. Furthermore, in HTS programs, a positive signal is always preferred than a negative one due to enhanced sensitivity and enabling the assay to be performed with minimal depletion of substrate. Our assay gives positive signal by converting ADP to ATP and not depletion of ATP, thus providing very high sensitivity and an HTS ready format.

Finally, compared with those luminescent assays listed above, our assay utilizes a genetically evolved firefly luciferase (UltraGlo luciferase) that acquired 70 mutations to ensure its robustness, thermal stability and resistance to false hit generation [41,42]. Furthermore, this enzyme when used in our system generates a very stable signal with a half-life of over $2 \mathrm{~h}$, ensuring a batch processing of screening plates that suits HTS scheduling format and in fact the data-generated always referred to as steady signal versus flash signal that is generated using other luciferases [41].

We also demonstrate that the assay can use any enzyme substrate combination without any limitation 
on the nature of the substrate or the need to modify it with fluorescent compounds or conjugation to biotin or other tags (see discussion below). The results presented here clearly demonstrate that these enzymes do not only use peptide substrates derived from histone proteins, but also can methylate full length histones in vitro and the assay can perfectly detect these activities. Furthermore, we also show that not only peptides, full length proteins, but also nucleosomes containing the octameric histones can be used. This feature makes it an ideal assay to screen for potential substrates that mimic the native environment in which chromatin can be used and is not limited to a set of peptides or proteins as substrates.

Because the assay does not rely on the use of antibodies, it does not suffer from any issue related to the quality of antibodies. This becomes a very critical factor when antibodies directed toward different methylation states of the substrate are used. When, substrates such as those nonmethylated, monomethylated, dimethylated and trimethylated lysine, symmetrically dimethylated and asymmetrically dimethylated arginine and monomethylated and nonmethylated arginines are used, cross reactivity of the antibodies can be of a concern. Furthermore, the assay can use high concentrations of any substrate, SAM or peptides, proteins or nucleosome, a feature that cannot be met when using assays such as AlphaLISA where peptide concentrations higher than $100 \mathrm{nM}$ results in the HOOK effect in which readout drops dramatically when exceeding this concentration of peptide [29]. Similar concern arises when using fluorescence polarization-based assays and fluorescently labeled tracers where high concentrations of fluorescently labeled peptides diminish the polarization window resulting in a narrow signal window. This assay also does not have any lag phase that is observed with other assay, that is, the activity is commensurate with enzyme activity starting from time zero without accompanying lag phase [29]. Other assays such as EPIGEN Methyltransferase assay suffer from similar drawbacks such a fluorescence interference and the need to ensure high quality of antibodies as well as the need for antibody optimization depending on the activity of the enzyme and the amount of substrate used [28]. The fluorogenic methyltransferase assay which relies on the use of thiol reactive fluorogenic dye CPM [27] is intolerant to reducing agents such as DTT and $\beta$-mercaptoethanol which may be required for enzymatic activity. Furthermore, free cysteine residues of methyltransferases could react with the thiol reactive dye and increase the background. Besides, this assay which is based on measuring fluorescence at 469 $\mathrm{nm}$ is subject to fluorescence interference from many of the compounds during libraries screens since many of them are excited and emit within similar range of wavelengths [27]. Thus, this assay and similar fluorescent assays maybe useful for enzyme characterization but are not suitable for HTS.

The bioluminescent assay described here does not also rely on the use of radioactivity such as HotSpot format which is based on filter-binding capture of substrates [25]. Besides being radioactive which cause health hazards and costly with respect of waste disposal, the assay is limited to the use of low concentrations of peptide or protein depending on the binding capacity of the filter paper.

The assay as described is a biochemical assay that monitor the enzymatic activity of purified methyltransferases by using the universal substrate (SAM) and detecting the universal product (SAH) using luminescence-based detection system in a homogenous high-throughput format. Thus, it is ideal for enzymatic activity measurements of purified enzymes and for drug discovery programs that carry out screening campaigns using a large set of chemical libraries. The assay is not meant to be used with cell extracts since they contain ATP which will interfere with the readout of this method. Thus, one of the major weakness of this assay is that it cannot be used with cell extracts containing methyltransferases. To overcome this drawback, immunoprecipitation of the enzyme of interest can be done and the immunoprecipitate can be used to test for enzyme activity. Furthermore, the assay does not interrogate and identify methylation sites which can be done using Mass spectrometry or ChIP-based assays. The site specific methylation which is part of the proteomic analysis of the methylome can be identified using such techniques.

Finally, the assay main liability is its use of multiple enzymes which might results in few false hits depending on the composition of the chemical library. However, as alluded to earlier in the result section, we have only observed one compound that inhibited the luciferase significantly and two compounds that inhibited the assay by only $40 \%$ at $10 \mu \mathrm{M}$ concentrations. The formulations of the assay make it robust to the interference from compounds that are similar to luciferin since we use high concentration of luciferin and we also used an Ultraglo ${ }^{\circledast}$ luciferase enzyme that has been proven in many other luminescent assays to be resistant to diverse chemical compounds due to its unique sequence and buffer formulations [41,42]. It is noteworthy that in drug discovery programs, it is always advisable to use orthogonal assays that are based on completely different principles to verify the correct calling of hits.

\section{Conclusion}

Methyltransferase-Glo is a homogenous and bioluminescent assay to monitor the activity of methyltransferases. It is not radioactive and is antibody free and 
thus does not incur issues related to safety and quality of the antibodies. Because of its universality, it can be used to detect the activity of diverse classes of methyltransferases and diverse classes of substrates (peptides, proteins, nucleic acids, nucleosomes, small molecules, etc.). It can detect methylation on lysine and arginine residues on proteins, and cytosine on nucleic acids. The assay is very sensitive and thus it requires small amounts of enzymes, a highly desirable feature for drug discovery research programs. The assay is easy to use and robust as shown by its high $Z^{\prime}$ and $Z$ values of over 0.7 , and by its low CV. Screening a library of pharmacologically active compounds resulted in very few false hits supporting its resistance to chemical interference and its utility in drug discovery programs searching for methyltransferases modulators.

\section{Future Perspective}

It is anticipated that epigenetics as a genaral research area will be of significant value in understanding cellular development, proliferation and transformation. Methylation of micro- and macro-molecules is at the forefront of epigenetics research in general and implications in disease processes in particular.

\section{Financial \& competing interests disclosure}

All authors are employees of Promega Corporation. The authors have no other relevant affiliations or financial involvement with any organization or entity with a financial interest in or financial conflict with the subject matter or materials discussed in the manuscript apart from those disclosed.

No writing assistance was utilized in the production of this manuscript.

Executive summary

- Developed a luminescent and homogenous assay (MTase Glo) to monitor the activity of methyltransferases.

- MTase Glo is nonradioactive, antibody-free and not fluorescent-based assay.

- MTase Glo is universal enabling the determination of enzyme activity of diverse families of methyltransferases such as DNA methyltransferases and protein methyltransferases.

- MTase Glo is capable of monitoring enzyme activity using diverse substrates regardless of the structure or nature of the substrate (peptides, proteins, nucleic acids or nucleosomes, among others.).

- MTase Glo is robust with a Z' value of over 0.7 and detects as low as 20-30 nM of S-adenosyl-L-homocysteine, the universal reaction product.

- MTase Glo protocol is simple and easy to use two-step protocol and gives reliable data using enzyme inhibitors.

- The assay is formatted into high-throughput screening setup using multiwall plates for use in an high-throughput screening campaign to screen for modulators of methyltransferases.

\section{References}

1 Kundaje A, Meuleman W, Ernst J et al. Integrative analysis of 111 reference human epigenomes: Roadmap Epigenomics Consortium. Nature 518, 317-330 (2015).

2 Blancafort P, Jin J, Frye S. Writing and rewriting the epigenetic code for cancer cells: from engineered proteins to small molecules. Mol. Pharm. 83, 563-576 (2013)

3 Carr SM La, Thangue NB. Cell cycle control by methylationphosphorylation switch. Cell Cycle 10, 733-734 (2011).

4 Copeland RA. Molecular pathways: protein methyltransferases in cancer. Clin. Cancer Res. 19, 6344-6350 (2013).

5 Copeland RA, Solomon ME, Richon VM. Protein methyltransferases as a target class for drug discovery. Nat. Rev. Drug Discov. 8, 724-732 (2009)

6 Biggar KK, Li SS-C. Non-histone protein methylation as a regulator of cellular signaling and function. Nat. Rev. Mol. Cell Biol. 16, 5-17 (2015)

7 Bedford MT, Clarks SG. Protein arginine methylation in mammals: who, what, and why. Mol. Cell 33, 1-13 (2009).

8 Cheng D, Yadav N, King RW, Swanson MS, Weinstein EJ, Bradford MT. Small molecule regulators of protein arginine methyltransferases. J. Biol. Chem. 279, 23892-23899 (2004).
9 Luo M. Current chemical biology approaches to interrogate protein methyltransferases. ACS Chem. Biol. 7, 443-463 (2012).

10 Masaki O, Daphne WB, Haber DA, Li EN. DNA methyltransferases Dnmt3a and Dnmt3b are essential for de novo methylation and mammalian development. Cell 99, 247-257 (1999).

11 Bestor TH, Edwards JR, Boulard M. Notes on the role of dynamic DNA methylation in mammalian development. Proc. Natl Acad. Sci. USA 112, 6796-6799 (2015).

12 Meyer KD, Jaffrey S. The dynamic epitranscriptome: N6methyladenosine and gene expression control Nat. Rev Mol. Cell Biol. 15, 313-326 (2014).

13 Stunnenberg HG, Vermueulen M, Atlasi Y. A Me6Age for pluripotency. Methylation of messenger RNA on the adenine base is critical for stem cell commitment and differentiation. Science 347, 614-615 (2015).

14 Marsala SZ, Gioulis M, Ceravolo R, Tinazzi M. A systematic review of catechol-O-methyltransferase inhibitors: efficacy and safety in clinical practice. Clin. Neuropharmacol. 35, 185-190 (2012).

15 Kiss LE, Soares-da-Silva P. Medicinal chemistry of catechol O-methyltransferase (COMT) inhibitors and their therapeutic utility. J. Med. Chem. 57, 8692-8717 (2014). 
16 Mato JM, Carrales FJ, Lu SC, Avila MA.

$S$-adenosylmethionine: a control switch that regulates liver function. FASEB J. 16, 15-26 (2002).

17 Lieber CS, Packer L. S-adenosylmethionine: molecular, biological, and clinical aspects- an introduction. Am. J. Clin. Nutr. 76, 1148S-1150S (2002).

18 Fontecave M, Atta M, Mulliez E. S-adenosylmethionine: nothing goes to waste. Trends Biochem. Sci. 29, 243-249 (2004).

19 Lu Q, Quinn AM, Patel MP et al. Perspectives on the discovery of small-molecule modulators for epigenetic processes. J. Biomol. Scr. 17, 555-571 (2012).

20 Best JD, Carey N. Epigenetics therapies for non-oncology indications. Drug Dis. Today 15, 1008-1014 (2010).

21 Szyf M. Prospects for the development of epigenetic drugs for CNS conditions. Nat. Rev Drug Discov. 14, 461-474 (2015).

22 Mozzetta C, Boyarchuk E, Pontis J, Ait-Si-Ali S. Sound of Silence: the properties and functions of repressive Lys methyltransferases. Nat. Rev. Mol. Cell Biol. 16, 499-513 (2015).

23 McGrath J, Trojer P. Targeting histone lysine methylation in cancer. Pharmacol. Ther. 150, 1-22 (2015).

24 Kaniskan HU, Konze KD, Jin J. Selective inhibitors of protein methyltransferases. J. Med. Chem. 58, 1596-1629 (2015).

25 Horiuchi KY, Eason MM, Ferry JJ et al. Assay development for histone methyltransferases. Assay Drug Dev. Technol. 11, 227-236 (2013).

26 Rather P, Cheng X, Jeltsch A. Continuous enzymatic assay for histone methyltransferases. BioTechniques 43, 602-608 (2007).

27 Wang R, Ibáńez G, Islam K et al. Formulating a fluorogenic assay to evaluate $\mathrm{S}$-adenosyl-L-methionine analogues as protein methyltransferase cofactors. Mol. BioSyst. 7, 2970-2981 (2011).

28 Klink TA, Staeben M, Twesten K et al. Development and validation of a generic fluorescent methyltransferase activity assay based on the transcreener AMP/GMP assay. J. Biomol. Scr. 17, 59-70 (2012).

29 Simard JR, Plant M, Emkey R, Yu V. Development and implementation of a high-throughput AlphaLISA assay for identifying inhibitors of EZH2 methyltransferase. Assay Drug Dev. Tech. 11, 152-162 (2013).

30

Quinn AM, Allali-Hassani A, Vedadi M, Simeonov A. A chemiluminescence-based method for identification histone lysine methyltransferase inhibitors. Mol. BioSyst. 6, 782-788 (2010).

31 Drake KM, Watson VG, Kisielewski A, Glynn R, Napper AD. Sensitive luminescent assay for the histone methyltransferase NSD1 and other SAM-dependent enzymes Assay Drug Dev. Technol. 12, 258-271 (2014).

32 Hemeon I, Gutierrez JA, Ho M-C, Schramm VL. Characterizing DNA methyltransferases with an ultrasensitive luciferase-linked continuous assay. Anal. Chem. 83, 4996-5004 (2011).

33 Ibanez G, McBean JL, Astudillo YM, Luo M. An enzymecoupled ultrasensitive luminescence assay for protein methyltransferases. Anal. Biochem. 401, 203-210 (2010).

34 Maegley KA, Krivacic C, Bingham P, Liu W, Brooun A. Comparison of a high-throughput mass spectrometry method and radioactive filter binding to assay the protein methyltransferase PRMT5. Assay Drug Dev. Technol. 13, 235-240 (2015).

35 Zhang JH, Chung TD, Oldenburg KR. A simple statistical parameter for use in evaluation and validation of high throughput screening assays. J. Biomol. Screen. 4, 67-73 (1999).

36 Anglin JL, Song Y. A medicinal chemistry perspective for targeting histone $\mathrm{H} 3$ lysine-79 methyltransferase DOT1L. J. Med. Chem. 56, 8972-8983 (2013).

37 McCabe MT, Orr HM, Ganji G et al. EZH2 inhibition as a therapeutic strategy for lymphoma with EZH2-activating mutations. Nature 492, 108-112 (2012).

38 Knutson AK, Wigle TJ, Warholic NM et al. A selective inhibitor of EZH2 blocks H3K27 methylation and kills mutant lymphoma cells. Nat. Chem. Biol. 8, 890-896 (2012).

39 Zheng W, Ibanez G, Wu H et al. Sinefungin derivatives as inhibitors and structure probes of protein lysine methyltransferase SETD2. J. Am. Chem. Soc. 134, 18004-18014 (2012).

40 Masson P, Adarbes V, Bocart S, Estevez S, Loillier B, Espanel X. Hit identification on G9a by AlphaLisa ${ }^{\mathrm{TM}}$ technology and hit confirmation using MT-Glo ${ }^{\mathrm{TM}}$. SLAS Abstract (2015).

41 Tanega C, Shen M, Mott BT et al. Comparison of bioluminescent kinase assays using substrate depletion and product formation. Assay Drug Dev. Technol. 7, 606-614 (2009).

42 Auld DS, Southall NT, Jadhav A et al. Characterization of chemical libraries for luciferase inhibitory activity. J. Med. Chem. 51, 2372-2386 (2008). 